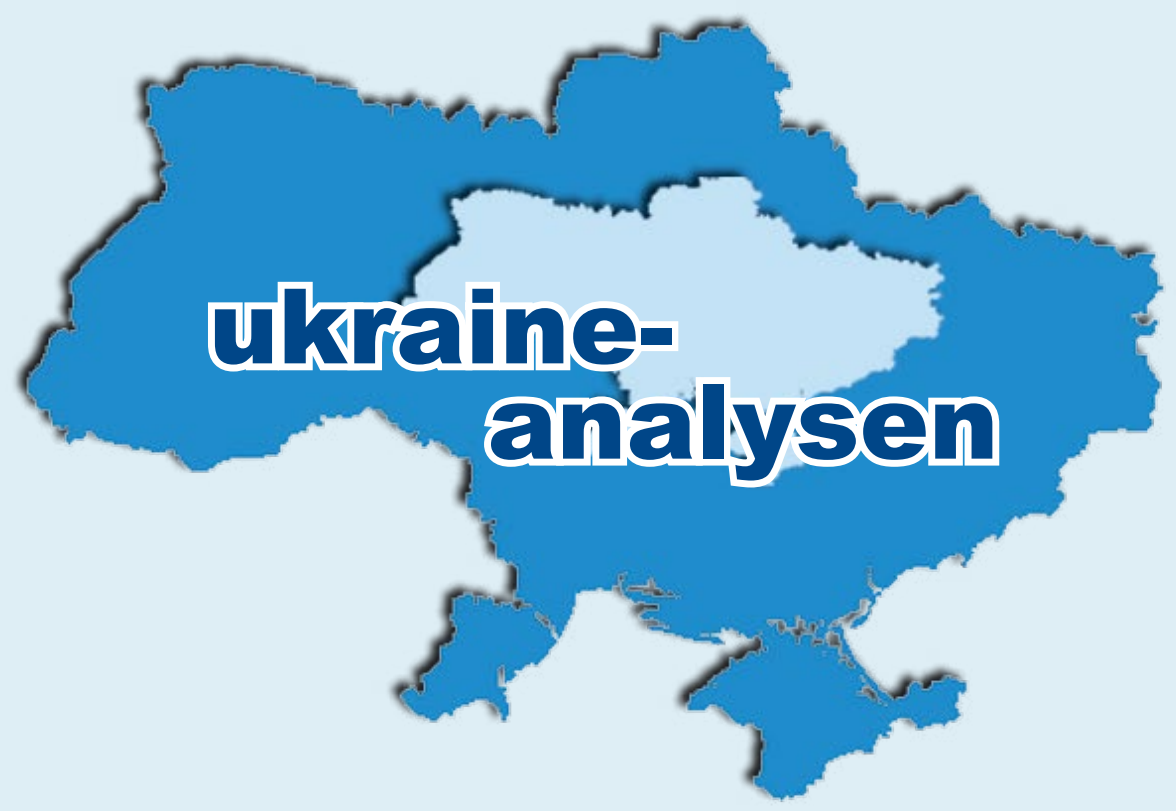

www.laender-analysen.de/ukraine

\title{
DIE LOKALWAHLEN
}

ANALYSE

Die ukrainische Regierung auf dem Prüfstand: Die Regional- und Kommunalwahlen vom

25. Oktober 2015

Von Dmitri Stratievski, Berlin

- ANALYSE

Subnationaler Autoritarismus in der Ukraine von Janukowitsch bis Poroschenko:

Eine Fallstudie über die östlichen Regionen

Von Mark Teramae, Helsinki

- TABELLEN UND GRAFIKEN ZUM TEXT

Steuern, Bruttoregionalprodukt der östlichen Regionen und Stimmen für Janukowitsch

- ANALYSE

Die Lokalwahlen 2015 in Transkarpatien

Von Oleg Friesen, München

- TABELLEN UND GRAFIKEN ZUM TEXT

Die Resultate der Lokalwahlen 2015 für das transkarpatische Regionalparlament

- DOKUMENTATION

Auszüge aus der Erklärung der internationalen Wahlbeobachter-Mission (IOEM) 17

Auszüge aus der Erklärung des ukrainischen Bürgernetzes OPORA 18

Die Rede von Präsident Poroschenko zu den Lokalwahlen 2015 19

DOKUMENTATION

Die vorläufigen Ergebnisse der Lokalwahlen 2015

DOKUMENTATION

Untersuchungsbericht des Europarates zu den Ereignissen in Odessa vom 2. Mai 2014

- CHRONIK

26. Oktober - 8. November 2015 


\section{Die ukrainische Regierung auf dem Prüfstand: Die Regional- und Kommunalwahlen vom 25. Oktober 2015}

Von Dmitri Stratievski, Berlin

\section{Zusammenfassung}

Die ukrainische Lokalwahl 2015 bezweckte nicht nur eine neue Zusammensetzung der kommunalen Legislativen. Sie stellte außerdem sowohl das Managementgeschick der Regierung als auch das neue Wahlgesetz auf die Probe. Darüber hinaus ist sie im Kontext der geplanten Dezentralisierung der Verwaltungsetagen zu sehen. Im Ergebnis hat der Staatspräsident Petro Poroschenko seine Machtposition wesentlich gestärkt und sogar erweitert. Auch wenn die Abstimmung am 25. Oktober größtenteils frei und fair verlaufen ist, zeigte sie doch deutlich viele Defizite der ukrainischen Wahlgesetzgebung. Für politische Neueinsteiger gab es kaum Erfolgsaussichten. Auf die Frage, ob die ukrainische Bevölkerung hinter dem Dezentralisierungsvorhaben der Regierung steht, bietet das Wahlergebnis keine abschließende Antwort, weil dieses Konzept für viele Ukrainer weitgehend unverständlich ist.

\section{Einleitung}

Angesichts der geplanten Dezentralisierungsreform wird die Bedeutung der Kommunalmandate und Bürgermeisterposten in der Ukraine steigen. Aus diesem Grund wird den turnusmäßigen Wahlen vom 25. Oktober eine besondere Bedeutung beigemessen. Insgesamt sollten etwa 170.000 Abgeordnete der über 10.000 Gemeinderäte gewählt werden. Für die landesweit 358 Bürgermeisterämter, unter anderem in den Metropolen Kiew, Odessa, Charkiw und Dnipropetriwsk, kandidierten mehr als 2.700 Personen. 142 Parteien haben sich bereit erklärt, um die Wählergunst in allen Regionen des Landes - bis auf die Krim, Sewastopol und die separatistisch kontrollierten Teile der Ostukrainezu kämpfen. 132 von ihnen wurden zur Wahl zugelassen.

Die Zentrale Wahlkommission erklärte im Vorfeld, in weiten Teilen der Ostukraine sei die Durchführung des Wahlprozederes aus Sicherheitsgründen unmöglich. Davon waren 91 Gemeinden im Gebiet Donezk und 31 Gemeinden im Gebiet Luhansk betroffen. Mit den Binnenflüchtlingen konnten an diesem Tag insgesamt etwa 1,5 Millionen wahlberechtigte ukrainische Bürger von ihrem Wahlrecht keinen Gebrauch machen.

Zum Auftakt der Wahlen bezeichnete Petro Poroschenko die bevorstehende Abstimmung als »dritte Etappe des Neustarts in der Machtstruktur« und setzte unmissverständlich seine Prioritäten: "proukrainische Mehrheiten« in allen Ecken der Ukraine und zügige Reformen gleich nach dem Tag der Abstimmung. So verband der Staatspräsident sein politisches Schicksal indirekt mit dem Wahlergebnis.

\section{Der Kontext: die Dezentralisierungsreform und das Wahlgesetz}

Der ukrainische Staat leidet seit 1991 unter unverhältnismäßiger Zentralisierung. Die Kommunen haben wenig Machthebel und finanzielle Kapazitäten, um Probleme vor Ort unbürokratisch zu lösen. Das mindert die Hand- lungsfähigkeit der lokalen Verwaltung und erschwert ihre Kommunikation mit der Bevölkerung. Die ukrainische Führung suchte nach einer Möglichkeit, die politischen Prozesse im Land zu kanalisieren und Paragraph 11 des Minsker Abkommens vom Februar 2015 (in der englischen Fassung »decentralization «) zu implementieren. Im April 2015 tagte zum ersten Mal die Verfassungskommission unter dem Vorsitz des Parlamentspräsidenten Wolodymyr Grojsman, der mehrere Rechtswissenschaftler, Richter sowie drei Ex-Staatsoberhäupter angehörten. Sie beschäftigte sich unter anderem mit einem möglichen Dezentralisierungskonzept. Im August 2015 brachte Petro Poroschenko den Gesetzentwurf "Über die Verfassungsänderung bezüglich der Dezentralisierung der Macht» ins Parlament ein. Sein Kernstück ist die Übertragung kommunalpolitischer Befugnisse an die entsprechenden lokalen Stellen. Dieser Vorschlag ähnelt der polnischen Reform, die in dem ebenfalls unitären Nachbarland seit 1999 stufenweise umgesetzt wird. Im Plenarsaal votierten zwei Koalitionsfraktionen entschlossen dagegen, die Vaterlandspartei unter Julia Timoschenko und die Radikale Partei von Oleh Ljaschko. Die dritte politische Kraft, die Selbsthilfe von Andrij Sadowyj, kehrte der Gesetzesvorlage ebenfalls mehrheitlich den Rücken. Ihre fünf Abweichler wurden aus der Fraktion ausgeschlossen. Am Abstimmungstag kam es vor dem Parlamentsgebäude zu blutigen Zusammenstößen zwischen Nationalisten und Sicherheitskräften, bei denen vier Polizisten starben. Petro Poroschenko stellte die für die erste Lesung notwendige einfache Mehrheit nur mithilfe von Stimmen aus dem Lager der Opposition und der Fraktionslosen her. Die für das endgültige positive Votum des Parlaments erforderliche Verfassungsmehrheit wird der ukrainische Staatschef im Dezember zu erreichen versuchen.

Die oben beschriebene Gemengelage macht anschaulich, wie stark dieses Thema die ukrainische Gesell- 
schaft bewegt und polarisiert. Nicht zuletzt geht es um Begrifflichkeiten. Dezentralisierung wird oftmals irrtümlich mit Föderalisierung verwechselt, die für bedeutende Teile der politischen Elite und der Bevölkerung der Ukraine negativ konnotiert ist. Daraus resultiert die Ablehnung des Dezentralisierungsmodells als einem aus Russland importierten Produkt, das gegen die ukrainische Staatlichkeit gerichtet würde und in die Hände der Separatisten spielen sollte. Dabei ist zu bemerken, dass im Land so gut wie keine Aufklärungskampagne zum Dezentralisierungskonzept in die Wege geleitet wurde bzw. wenig öffentliche Debatten stattfanden. Diese Tatsache schürt Ängste und bekräftigt Vorurteile.

Die ukrainische Wahlgesetzgebung wurde im Laufe der Zeit mehrfach verändert. Das letzte Wahlgesetz aus dem Jahr 2011 besiegelte die Rückkehr zu einem gemischten Wahlsystem. Im Juli 2015 verabschiedete die Werchowna Rada das Gesetz „Über die Lokalwahlen«. Das Mischmodell bleibt in einer modernisierten Fassung erhalten. Auf der kleinsten Gemeindeebene (Dorf und Siedlung) wird nach dem Mehrheitswahlrecht gewählt, für die restlichen Kommunen (Bezirk, Stadt und Gebiet) gilt ein Verhältniswahlrecht. Die Parteien erstellen ihre Listen und schicken einen Kandidaten pro Wahlkreis ins Rennen. Es werden keine Wahlbündnisse zugelassen. Für Bürgermeisterwahlen gibt es zwei Regelungen. In Städten mit mehr als 90.000 Einwohnern müssen die beiden Kandidaten mit dem höchsten Stimmanteil in eine Stichwahl gehen, wenn sie im ersten Wahlgang weniger als 50\% der Stimmen auf sich vereint haben. Für kleinere Ortschaften ist keine Stichwahl vorgesehen. Der ukrainische Wähler hat eine Stimme. Kritiker meinten, das neue Gesetz verfestige eine Monopolstellung der örtlichen Parteiverbände. Der Stellvertretende Vorsitzende der Zentralen Wahlkommission Andrij Magera betitelte das in Kraft getretene Wahlwesen als »Rückschritt bei der Entwicklung eines funktionsfähigen Wahlsystems« und zog Parallelen zum aus seiner Sicht negativen Beispiel Russlands. Trotz der Kritik gab es bis zum Abstimmungstag keine Novellierung der entscheidenden Paragraphen des Wahlgesetzes. Eine Änderung vom September 2015 regelt nur freiwillige Gemeindefusionen mit dem Ziel, Wahlen synchron durchzuführen und Kosten zu sparen.

\section{Der Wahlkampf}

Die politische Landschaft der Ukraine hat sich im Vergleich zur letzten Kommunalwahl 2010 gravierend verändert. Zwei vormals große Spieler, die Partei der Regionen und die Kommunisten, die mindestens ein Jahrzehnt in mehreren Gebiets- und Stadtparlamenten im Osten und Süden des Landes dominiert hatten, waren nicht mehr am Wahlrennen beteiligt. Während die landesweiten Galionsfiguren dieser Parteien inzwischen aus der aktiven Politik ausgeschieden sind, wechselten ihre Gefolgsleute vor Ort die Parteifahne und sind weiterhin bedeutsame Akteure im Südosten der Ukraine. So war der amtierende Bürgermeister von Odessa, Gennadij Truchanow, der wieder kandidierte, bis vor kurzem Fraktionsvorsitzender der Partei der Regionen im Stadtrat. Sein Parteikollege, der heutige Kandidat für den Bürgermeisterposten in Dnipropetriwsk Oleksandr Wilkul, gehörte als Stellvertretender Ministerpräsident der ukrainischen Regierung unter Wiktor Janukowitsch an. Zugleich spielten die Vertreter der vormaligen Elite in den Listen der Regierungsparteien eine herausragende Rolle. Eineinhalb Jahre nach dem Machtwechsel in Kiew etablierte sich eine neue Machtpartei, der Block Petro Poroschenko-Solidarität (BPP-Solidarität), der vielen Apparatschiks der Janukowitsch-Ära Asyl angeboten hat.

Darüber hinaus war eine offene politische Konkurrenz zwischen den Mitgliedern der Regierungskoalition in Kiew eher schwierig. In erster Linie betraf das die Vaterlandspartei. Julia Timoschenko kritisierte mehrfach im Parlament das Wirtschaftsprogramm der Regierung. Ihre lokalen Politiker zeigten sich dagegen loyal gegenüber Kiew und verwiesen auf die Notwendigkeit des Zusammenhalts der ukrainischen Gesellschaft im Hinblick auf »die russische Aggression«. Für eine Überraschung sorgte Premier Arsenij Jazenjuk, dessen Volksfront-Partei noch im August auf ihre Wahlteilnahme verzichtete. Die Volksfront ist seit Monaten im Tiefflug. Eine spürbare Wahlniederlage seiner Partei hätte die Stellung des ukrainischen Ministerpräsidenten weiter geschwächt. Die Partei UDAR des Kiewer Bürgermeisters Witalij Klitschko agierte weiterhin als Teil der Poroschenko-Partei und hat an Profil verloren. Der Oppositionsblock griff das tagespolitische Handeln der Regierung an. Diese Kritik hatte aber keinen grundsätzlichen Charakter und war nicht programmatisch verankert, wie es von einer führenden europäischen Oppositionspartei zu erwarten ist. Sie trug in weiten Teilen die Züge einer "Schaufensterpolitik». Zum Beispiel stellte der »Ministerpräsident des Schattenkabinetts« Borys Kolesnikow die Arbeitslosigkeit als zentralen Kritikpunkt an der Regierung in den Vordergrund. Der Vorsitzende des Parteiverbands im Gebiet Saporishshja, Wiktor Busko, betonte in seiner programmatischen Rede die „Fachkompetenz« seines Teams. Gleichzeitig beklagten seine Parteikollegen den maroden Zustand der städtischen Parkanlagen, obwohl sie in ihrer Eigenschaft als Mitglieder der Partei der Regionen lange Zeit in der Stadt- und Gebietsverwaltung in Regierungsverantwortung gewesen waren. Insgesamt waren die Lokalwahlen durch die Teilnahme vieler kleiner Parteien gekenn- 
zeichnet, die außerhalb ihrer Stammregion nur einen bescheidenen Bekanntheitsgrad haben. Die Mehrzahl von ihnen, zum Beispiel die Partei Vertraue den Taten in Odessa, diente ausschließlich dem Ziel, ihren Spitzenmann zu unterstützen und Mehrheiten in der lokalen Legislative zu schaffen.

Der Wahlkampf stand im Zeichen der Gesamtsituation im Lande. Die Kandidaten konzentrierten sich wenig auf klassische kommunale Probleme wie Wohnen, Verkehr oder Infrastruktur. Sie mussten sich mit breiten innen- und außenpolitischen Fragenkomplexen auseinandersetzen wie etwa der Wirtschaftskrise, dem Verhältnis zu Russland, EU- und NATO-Beitrittsperspektiven, der Krim-Frage, Frieden oder Sieg im Donbass und Ähnlichem, auch wenn sie im Fall ihrer Wahl mit den vorhandenen regionalpolitischen Werkzeugen kaum einen Beitrag zur Lösung dieser Aufgaben leisten können. Angesichts der ungeklärten Kompetenzen zwischen Kiew und den Regionen infolge der bevorstehenden Dezentralisierungsreform sowie der leeren Kommunalkassen fiel es allen Anwärtern auf Dorfoder Stadtratsmandate recht schwer, realisierbare Versprechungen abzugeben. Inhaltlich beschränkten sich die wichtigsten Akteure auf vier wesentliche Themen: 1 . Senkung der Betriebskosten für Privathaushalte. Darauf hatten Oppositionsblock, Radikale Partei und Vaterlandspartei bestanden. 2. Patriotismus als tragendes Element der ukrainischen Gesellschaft, Abschied von der sowjetischen Vergangenheit (national gesinnte Parteien, UKROP, Radikale Partei). 3. Stabilität und Frieden (Oppositionsblock, Unser Region, Wiedergeburt), 4. Wirtschaftsreformen, Fortsetzung des aktuellen Regierungskurses (BPP-Solidarität). So wurde de facto nur ein einziges kommunalpolitisches Thema landesweit flächendeckend aufgegriffen, nämlich die unzumutbaren Mietnebenkosten. Infolge dieser Ideenlosigkeit wurde das Wahlkampffeld in mehreren Fällen den Populisten überlassen. Alternativ setzte man auf Lokalpatriotismus. So hat zum Beispiel der Kandidat für das Bürgermeisteramt in Dnipropetrowsk, Borys Filatow, die Kernthese seines Wahlprogramms wie folgt präsentiert: "Die Bevölkerung in der Geldgeberregion, die das (wirtschaftliche - D. S.) Rückgrat des Landes bildet, muss ein besseres Leben führen als die anderswo.«

\section{Wahltag und Wahlergebnis}

Die Wahlbeteiligung lag bei 46,6\% und war damit noch niedriger als bei den letzten Lokalwahlen 2010. Laut der Zentralen Wahlkommission gingen damals 48,8\% der Wahlberechtigten zur Urne. Wie schon in den Vorjahren waren auch 2015 die Westukrainer am aktivsten: In der Region Ternopil lag die Wahlbeteiligung bei $56,5 \%$, in Lwiw bei $56,31 \%$ und in Wolhynien bei $55,29 \%$. Im
Süden waren die Wähler wesentlich passiver. In Cherson betrug die Wahlbeteiligung 37,41\%, in Mylolajiw $38,48 \%$. Am niedrigsten war die Wahlbeteiligung in den Gebieten Donezk (31,65\%) und Luhansk (35,27\%).

Zahlreiche Quellen berichteten über Gesetzwidrigkeiten und Manipulationen im Laufe des Wahlkampfs und am 25. Oktober. Die Abstimmung wurde in vielen Regionen der Ukraine von Stimmenkäufen überschattet, deren Ausmaß allerdings deutlich geringer war als bei den Lokalwahlen im Jahr 2010, so das Urteil eines landesweiten Netzwerks von unabhängigen Wahlbeobachtern. Der Wählerschaft bot man Lebensmittelpakete an. Studierende sollten mit einer »kleinen Prämie» motiviert werden. Am Wahltag wurde unerlaubte Parteiwerbung verteilt, deren Farbkombination mit dem Wahlzettel übereinstimmte. Am 25. Oktober erhielten Handynutzer bis zur Schließung der Wahllokale kurze Werbeapelle im SMS-Format.

Obwohl in mehreren Wahlkreisen der ostukrainischen Gebiete Donezk und Luhansk außerhalb der separatistisch kontrollierten Landstriche, unter anderem in den ukrainischen Städten Mariupol und Krasnoarmijsk, keine Wahlen stattfanden bzw. diese für ungültig erklärt wurden, gab es für die Mehrheit der wahlberechtigten Ukrainer eine sichere Möglichkeit, frei für eine politische Kraft ihrer Wahl zu votieren. Das ist das wichtigste Ergebnis dieser Wahlen. Die internationalen Beobachter kritisierten zwar das Wahlgesetz und prangerten Unregelmäßigkeiten an, stellten jedoch nicht das Gesamtprozedere in Frage. Der deutsche Außenminister Frank-Walter Steinmeiner kommentierte die Wahlen wie folgt: »Es ist gut, dass die Lokalwahlen am 25.10. in der Ukraine trotz des schwierigen Umfelds ohne größere Zwischenfälle stattfinden konnten. Die OSZE/ODIHR-Mission hat in einer ersten Stellungnahme einen grundsätzlich ordentlichen und transparenten Prozess der Stimmabgabe und -auszählung festgestellt.« Generell haben die Wahlkommissionen vor Ort und indirekt auch die ukrainische Exekutive diese Härteprobe überstanden. Das amtliche Wahlergebnis steht noch in keiner Region der Ukraine fest. In einigen Städten müssen die Bürgermeisterkandidaten am 15. November in einer Stichwahl antreten, zum Beispiel in Kiew, Dnipropetrowsk und Sumy. Es sind zahlreiche Gerichtsklagen zu erwarten. Trotzdem erlauben die vorhandenen Daten folgende Schnellanalyse:

1. Entgegen den Hurra-Meldungen aus den Vorständen der Regierungsparteien kann die Koalition in der Werchowna Rada nicht mit einer stabilen Mehrheit auf kommunaler Ebene rechnen. Die PoroschenkoPartei hat gut abgeschnitten und erzielte in allen Landesteilen ein zweistelliges Ergebnis. Aus machtpolitischer Perspektive ist das eine wichtige Errun- 
genschaft. Dieses Ergebnis ist jedoch mit Vorsicht zu betrachten. Zum Beispiel stellt der PoroschenkoBlock in der südlichen Region Odessa, einer früheren Hochburg der Partei der Regionen, jetzt in den Kreisstädten sechs Bürgermeister. Vier davon sind allerdings ehemalige Mitglieder der JanukowitschPartei. Sie waren bis zuletzt amtierende Vorsitzende der Stadträte und wurden von der jetzigen Regierungspartei aufgestellt.

2. Gewinner der Wahl ist Petro Poroschenko, Verlierer Arsenij Jazenjuk, der bis vor kurzem als Präsidentschaftskandidat gehandelt wurde. Jetzt muss er um seinen Posten an der Regierungsspitze bangen. Die Rufe nach seinem Rücktritt werden lauter.

3. Die Vaterlandspartei und die Radikale Partei haben keinen gesamtnationalen Machtanspruch mehr. Die Timoschenko-Partei schaffte es nicht in den Stadtrat ihrer Heimatstadt Dnipropetrowsk. (2010: dritter Platz und acht Sitze). In Charkiw hat die Vaterlandspartei vor fünf Jahren das zweitbeste Ergebnis gleich nach der Partei der Regionen erzielt und mit 14 Sitzen eine Stadtratsfraktion gebildet. Heute scheiterte sie an der Fünfprozenthürde. Der ukrainische Politologe Wolodymyr Fesenko sprach von der Vaterlandspartei als »Partei der Dorfbewohner». Tatsächlich leben ihre Stammwähler von 2015 überwiegend in den ländlichen Gebieten der Zentralukraine. Im städtischen Raum erntete vor allem die UKROP die Stimmen der Timoschenko-Partei. Oleh Ljaschkos Radikale haben bei der vergangenen Wahl keine eigene politische Nische gefunden. Ihr Appell, eine landesweite Protestbewegung gegen die erhöhten Betriebskosten zu organisieren, war nicht neu. Dazu wurde im September noch Ljaschkos politischer Weggefährte Ihor Mosijtschuk aufgrund von Korruptionsvorwürfen festgenommen. In den Augen vieler Wähler war das eine Blamage, weil die Radikale Partei das Thema Korruptionsbekämpfung immer als Schwerpunkt behandelt hat.

4. Das Wahlergebnis der erst 2012 amtlich registrierten Selbsthilfe bedarf noch weiterer Auswertung. In der Westukraine, einschließlich ihrer Hochburg Lwiw, musste die Partei Stimmen einbüßen. Während Selbsthilfe aus der Parlamentswahl 2014 in den Regionen Lwiw, Iwano-Frankiwsk und Wolhynien als drittstärkste Kraft hervorgegangen ist (18,8\%, $18,3 \%$ und $11,5 \%$ ), wurde sie 2015 zwar teilweise zweitstärkste Partei, verlor aber je nach Region bis zu 4\%. Im Kampf um den Posten des Lwiwer Bür- germeisteramts verfehlte Andrij Sadowyj seine Wiederwahl knapp. Im Osten des Landes hat seine Partei dagegen gut Fuß gefasst. Sie profitierte vom Image der Mittelschichtspartei und zog mit dem zweibesten Regionalergebnis (12\%) in den Charkiwer Stadtrat ein. 2014 nahm Selbsthilfe in Charkiw Platz fünf ein und war mit 7,55\% der abgegebenen Stimmen deutlich schwächer.

5. Den Regierungsparteien ist es nicht gelungen, die neuorganisierten Reste der Partei der Regionen aus dem politisch-öffentlichen Leben zu vertreiben. Der Oppositionsblock und seine regionalen Ableger, die Bürgermeisterinitiative Unser Region sowie andere, mehrheitlich aus Repräsentanten der JanukowitschZeit bestehende Parteien behalten ihre festen Positionen im Südosten der Ukraine. Von einem Alleinregieren wie früher kann hier aber keine Rede mehr sein.

6. Die alten Netzwerke in den wichtigen ukrainischen Großstädten haben ihre Stärke und Überlebensfähigkeit bewiesen. In Odessa und Charkiw haben die politisch Altgedienten ihre Bürgermeisterposten verteidigt. Für ihre sichere Wiederwahl reichen die heute vorhandenen wirtschaftlichen und politischen Möglichkeiten sowie eine freundliche Haltung des Präsidialamts ihnen gegenüber aus. Jegliche Bemühungen, neue Strukturen zu installieren, haben sich am Wahltag als erfolglos erwiesen. In Odessa verfügt der örtliche Gouverneur Miheil Saakaschwili über wichtige Ressourcen (der örtliche Staatsanwalt und der Polizeichef sind Gefolgsleute von ihm aus Georgien) sowie über einen Ruf als Reformer. Ungeachtet dessen unterlag sein Wunschkandidat Oleksandr Borowik gegenüber dem amtierenden Bürgermeister Gennadij Truchanow. In Charkiw wurde der Bürgermeister Gennadij Kernes mit klarer Mehrheit wiedergewählt. In Transkarpatien gewann das Einheitszentrum von Witalij Baloha, der seit 2005 in der Region herrscht.

7. Die politischen Newcomer konnten als »unbefleckte Einsteiger« zwar mit einem gewissen Vertrauensvorschuss der Bevölkerung rechnen, waren in Wirklichkeit aber meistens chancenlos. Sie erzielten nur Einzelerfolge auf den kleinsten kommunalen Ebenen, etwa in Dorfräten oder kleinen Städten. In keiner ukrainischen Großstadt gewann ein politischer Neuling den Kampf ums Bürgermeisteramt oder gelangte auch nur in die Stichwahl.

Über den Autor

Dr. Dmitri Stratievski ist Politologe und Historiker sowie stellvertretender Vorsitzender des Osteuropa-Zentrums Berlin e. V. 


\section{Subnationaler Autoritarismus in der Ukraine von Janukowitsch bis Poroschenko: Eine Fallstudie über die östlichen Regionen}

Von Mark Teramae, Helsinki

\section{Zusammenfassung}

Die jüngsten Lokalwahlen in der Ukraine sind nur der neueste Indikator für das Fehlen jeglichen grundlegenden strukturellen Wandels im innenpolitischen System des Landes. Das Ende der Oligarchie war eine der Hauptforderungen der Euromaidan-Proteste, dennoch gehen die Ukrainer nicht mit einem, sondern mit drei großen Elitezirkeln ins Jahr 2016, angeführt von Präsident Petro Poroschenko, Ihor Kolomojskij und Rinat Achmetow. Die Partei der Regionen hat es unter dem damaligen Präsidenten Wiktor Janukowitsch geschafft, die rivalisierenden Elitegruppen unter dem Dach einer einzigen politischen Partei zu versammeln; nun wurden die verschiedenen Seilschaften durchtrennt, die etabliert worden waren, als das Donezker subnationale autoritäre Regime erst zu einem regionalen und dann zu einem landesweiten Regime ausgebaut wurde. Mit ihren diversen Oligarchen und deren regionalen, um die Vorherrschaft konkurrierenden Unterstützungszentren ähnelt die Situation in der Ukraine heute auf vielerlei Weise der in den 1990er Jahren. Mit einer Unmenge von bedeutungslosen Regionalparteien, die aus ebenjenen Mitgliedern der Partei der Regionen bestehen, derer sich das neue Regime entledigen sollte, ist die ukrainische Politik noch immer fest im gleichen Teufelskreis gefangen.

\section{Der Euromaidan als Orange 2.0}

Entgegen anderslautenden Behauptungen von einer nationalistischen Übernahme oder einer faschistischen Junta gründet die Mehrheit der Post-Janukowitsch-Interimsregierung auf Eliten, die der früheren Ministerpräsidentin Julia Timoschenko und ihrer Batkiwschtschyna-Partei sowie Petro Poroschenko, Ihor Kolomojskij und einigen prominenteren Euromaidan-Aktivisten nahe stehen. So war beispielsweise Interims-Ministerpräsident Arseni Jazenjuk Chef der Batkiwschtschyna-Partei, als Timoschenko im Gefängnis war, und Interims-Präsident Oleksandr Turtschinow steht Timoschenko seit deren gemeinsamer Zeit in Dnipropetrowsk in den 1990er Jahren nahe.

Von den 21 neu ernannten Ministern einschließlich des Sekretärs des Rats für Nationale Sicherheit und Verteidigung kamen 18 aus westlichen und zentralen Regionen, acht sind in Timoschenkos Batkiwschtschyna-Partei gewesen (unter ihnen auch zwei der drei aus der Ostukraine stammenden, Arsen Awakow und Ludmila Denisowa), sieben waren Oligarchen, parteilos oder kamen aus dem Militär und sechs gehörten der rechtsextremen nationalistischen Swoboda-Partei an (s. Ukraine-Analysen Nr. 129). Nicht neue Gesichter vom Maidan ersetzten den entmachteten Donezk-Klan und de facto nahezu jegliche Repräsentation der Ostukraine -, sondern Gegeneliten, unter ihnen viele alte Gesichter aus den Gruppen, die sich nach der Orangen Revolution um Juschtschenko und Timoschenko gebildet haben.

\section{Sturz der Orangen Ordnung: Donezk rückt von der Peripherie ins Zentrum der nationalen Politik}

Die Partei der Regionen wurde 1997 in Kiew als Partei der Regionalen Wiedergeburt gegründet, ihr gewählter Vorsitzender war der Bürgermeister von Donezk, Wolodymyr Rybak. Nachdem sie bei den Parlamentswahlen von 1998 weniger als ein Prozent der Stimmen erhalten hatte, unterstützte die Partei 1999 die Wiederwahl von Präsident Kutschma, 2000 bildete sie mit vier anderen Parteien einen Block, der als Partei der Regionalen Wiedergeburt - Arbeit und Solidarität der Ukraine bekannt ist. Einer ihrer Gründer war der derzeitige Präsident Poroschenko, der sein Geld und seine Unterstützung allerdings zurückzog und sich mit Wiktor Juschtschenko verbündete, als klar wurde, dass die Macht innerhalb des Donezker Elitezirkels verbleiben würde.

Nach der Umbenennung in Partei der Regionen im März 2001 wurde rechtzeitig zu den Parlamentswahlen von 2002 ein neuer Pro-Kutschma-Block gegründet. Im November 2002 löste Wiktor Janukowitsch, zu diesem Zeitpunkt Gouverneur der Donezk-Region, Anatolij Kinach als Ministerpräsident ab und verschaffte der Partei der Regionen einen ersten Vorgeschmack auf die landesweite Macht. Janukowitsch trat bei den Präsidentschaftswahlen von 2004 an, die er wegen Wahlfälschung blamabel verlor, es folgte jedoch sein schnelles Comeback, erst von 2006 bis 2007 als Ministerpräsident und dann 2010 als demokratisch gewählter Präsident.

Die in Donezk verankerte Partei der Regionen ist ein interessantes Phänomen, da sie das einzige Beispiel für 
ein lokales Regime ist, das sich in andere Regionen ausgebreitet hat, um dann in einem weiteren Schritt die zentralstaatliche Macht zu übernehmen. Edward Gibsons Konzept des subnationalen Autoritarismus beschreibt eine Region (einen Bundesstaat oder eine Provinz) in einem demokratischen Staat, die - einfach ausgedrückt nach ihren eigenen Regeln spielt, dabei jedoch durch nationale Gesetze und Normen beschränkt wird. In den bisherigen Fällen blieben diese Regionen allerdings eine Art autoritärer Inseln oder wurden allmählich von den Zentralmächten demokratisiert. Im ukrainischen Fall dominierten die subnationalen autoritären Regime die anderen Regionen und übernahmen auch die Zentralmacht. In weiten Teilen der postsowjetischen Region schränkten ein starker Präsident oder eine starke Partei die Macht der Regionen ein. Janukowitsch war kein Alexander Lukaschenko und kein Nursultan Nasarbaew, und er verfügte auch nicht über die Parteistruktur eines Vereinten Russland, schaffte es aber dennoch, genügend Seilschaften zwischen den politischen Eliten in den verschiedenen Regionen des Landes zu etablieren. Viel davon ist der spezifischen politischen Geographie in der Ukraine geschuldet, wo etwa das halbe Land bei den Wahlen eine Partei mit starken Verbindungen nach Russland unterstützt hat - das ist ein wichtiger Aspekt für die Regierungsfähigkeit der Partei der Regionen.

\section{Seilschaften - Schlüssel zur Etablierung der Macht}

Die Ukraine ist ein geteilter Staat, wobei sehr umstritten ist, in welchem Ausmaß sich das auf das tägliche Leben auswirkt. Das Ziehen klarer Trennlinien zwischen einem östlichen und einem westlichen oder einem prowestlichen und einem prorussischen Teil ist eine massive Vereinfachung; die Wahlergebnisse zeigen jedoch große Unterschiede zwischen östlicher und südlicher Ukraine auf der einen und westlicher und zentraler Ukraine auf der anderen Seite. Wie hat die Partei der Regionen es also geschafft, ein Land zu übernehmen, dessen Bevölkerung sie nur etwa zur Hälfte unterstützt? Vor allem drei Faktoren haben das möglich gemacht: Seilschaften zwischen verschiedenen Landesregionen, vor allem östlichen und südlichen, Seilschaften zwischen Zentralregierung und den Regionen, in denen Janukowitsch zum Präsidenten gewählt wurde, und Seilschaften zwischen Partei der Regionen und Russischer Föderation.

Nach der Orangen Revolution setzten die neuen Behörden mit dem früheren Präsidenten Leonid Kutschma verbündete Gruppen unter den Druck. Um ihre politischen Überlebenschancen zu erhöhen und/oder Strafverfolgung wegen begangener Verbrechen zu entgehen, begannen kleine unabhängige Parteien und lokale Eliten, sich der Partei der Regionen anzuschließen. Die behauptete, nicht nur Donezk, sondern die gesamte südliche und östliche Ukraine zu vertreten, obwohl die dortigen Eliten sich genauso ihre Wege in sämtliche Bereiche der Zentralmacht bahnten wie die meisten regionalstaatlichen Administrationen, nachdem Janukowitsch Präsident geworden war.

Werfen wir einen Blick auf die drei einflussreichsten Regionen der Ostukraine, Donezk, Dnipropetrowsk und Charkiw. Ein starker Indikator für die Seilschaften zwischen dem Zentrum und diesen Regionen findet sich in der Statistik über die Nettosteuerbewegungen. Grafik 1 auf S. 10 mit Daten zu 2013 zeigt einen Trend, der das genaue Gegenteil zu dem häufig wiederholten Mantra Donbass kormit stranu ("Der Donbass ernährt das Land") darstellt. Der Donbass hat nicht nur fast viermal weniger Steuereinnahmen ans Zentrum abgeführt als das benachbarte Dnipropetrowsk, er hat auch mehr Subventionen erhalten als Dnipropetrowsk und Charkiw zusammen. Laut Grafik 2 auf S. 10, die das Bruttoregionalprodukt der Regionen von 2013 zeigt, hat Donezk etwas mehr produziert als Dnipropetrowsk und fast doppelt so viel wie Charkiw. Angesichts der Bedeutung der Seilschaften und dem Umstand, dass Donezk das Herz der Partei der Regionen war, überrascht es nicht, dass hier mehr Steuern einbehalten und gleichzeitig zusätzlich Subventionen vom Zentrum bezogen wurden. Genauso wenig überrascht es, dass Dnipropetrowsk und Charkiw mehr ans Zentrum abführen mussten, um weiterhin Unterstützung aus Kiew zu erhalten.

\section{Russische Föderation wichtig fürs Überleben der Partei der Regionen}

Da die Ukraine ein so außergewöhnlicher Fall von subnationalem Autoritarismus ist, muss noch ein anderer Faktor für diese Ergebnisse relevant sein. Und hier kommt Russlands Rolle ins Spiel. Es gab mindestens drei relevante Wege des russischen Einflusses: die Ukrainische Orthodoxe Kirche - Moskauer Patriarchat (UOK-MP), bilaterale Abkommen zwischen Partei der Regionen und Vereintem Russland und Eliten, die in Im- oder Export von Gütern von und nach Russland involviert waren.

Es war kein Geheimnis, dass Russland 2004 Janukowitsch unterstützt hat. 2010 war Janukowitsch erneut der Kandidat, den der Kreml favorisierte, vor allem weil Partei der Regionen und Vereintes Russland 2005 ein bilaterales Kooperationsabkommen unterzeichnet hatten. Die russischen Aktionen waren jedoch viel weniger interventionistisch als 2004, als sich die Unterstützung für den Amtsinhaber Juschtschenko im einstelligen Bereich bewegte und seine einzige ernsthafte Herausforderin Timoschenko den russischen Interessen viel weniger zuwiderlief. Es gab auch persönliche Einmischun- 
gen russischer Politiker, etwa des ehemaligen Moskauer Bürgermeisters Juri Luschkow, der seit den 1990er Jahren Geld aus dem Haushalt der Stadt Moskau aufgewendet hatte, um Projekte auf der Krim zu finanzieren, etwa den Bau von Wohnungen für Familien russischer Offiziere der Schwarzmeerflotte, Kindergärten, Veteranenkrankenhäusern und Sanatorien. Außerdem wurde der Moskau-Sewastopol-Fonds mit Geldern zur Reparatur von Kasernen, dem Bau von Schulen, der Zahlung von Lehrergehältern und dem Kauf technischen Equipments unterstützt.

Die UOK-MP ist die größte orthodoxe Kirche der Ukraine, vor allem wenn man die Zahl ihrer Gemeinden zugrunde legt, obwohl anscheinend viele ihrer Anhänger zum Kiewer Patriarchat überwechseln, vor allem seit Ausbruch des Krieges im Donbass (s. Ukraine-Analysen Nr. 137). Die größte Unterstützung genießt die UOK-MP im Süden, im Zentrum und im Osten, es gibt allerdings auch verschiedene Bastionen der Unterstützung in westlichen Regionen, etwa in Wolhynien. Die UOK-MP wird häufig als Werkzeug zur Unterstützung der russischen Außenpolitik angesehen, so wurde ihr etwa vorgeworfen, sich offen auf die Seite des Janukowitsch-Regimes zu stellen, die Nachricht von der Russkiy Mir zu verbreiten und später auch, sich offen gegen Poroschenko zu stellen und den Separatismus zu unterstützen.

Gasimporte sind immer eine Haupteinnahmequelle der ukrainischen Eliten gewesen, besonders über Rosukrenergo, das Dmytro Firtasch gehört, und Gazprom. Viele der großen Oligarchen des Landes, etwa Firtasch, Rinat Achmetow, Wiktor Pintschuk und Timoschenko, waren in Gasgeschäfte mit Russland verwickelt, unter anderem in den Bereichen Gasimport, Pipelinebau und Verkauf von Metall, Kohle und Chemikalien. Der Oppositionsblock, der etwas mildere Nachfolger der Partei der Regionen - angeführt unter anderem von Boris Kolesnikow, Juri Boiko, Serhij Ljowotschkin, Natalia Korolewska und Michail Dobkin sowie offenbar noch immer von Achmetow unterstützt - hat starke Verbindungen zur Gasindustrie und ist eine der wenigen Bastionen des russischen Einflusses nach dem Fall Janukowitschs.

\section{Neue Seilschaften in der Post-Janukowitsch-Welt}

Die Partei der Regionen begann zu implodieren, als Janukowitsch um die Kontrolle über seine Partei kämpfen musste. Angesichts von drei bis fünf großen und auf verschiedenen Eliten basierenden Fraktionen in der Partei wurde die Politik gleichmäßiger Einnahmenverteilung in Vetternwirtschaft zugunsten der sogenannten Familienfraktion umgewandelt, der der Sohn des
Präsidenten Oleksandr und seine Verbündeten angehörten. Wäre die Partei der Regionen auch dann kollabiert, wenn die verschiedenen Elitegruppen fest hinter dem Präsidenten gestanden hätten, oder waren das Trauma und die Gewalt der Euromaidan-Proteste ein unausweichliches Todesurteil für das Regime? Sicher ist, dass die verschiedenen komplexen Seilschaften, die seit 2004 geknüpft worden waren, nun durchtrennt wurden und dass es ein Gerangel um die Errichtung neuer Seilschaften gab.

Hier ist es wiederum besonders interessant, die Regionen Donezk, Dnipropetrowsk und Charkiw zu betrachten, in denen die Wähler von 2004 bis 2012 die Partei der Regionen und bei den Parlamentswahlen 2014 den Oppositionsblock unterstützt haben, wobei sie in der Post-Euromaidan-Ära jeweils unterschiedliche Wege eingeschlagen haben. In Teilen von Donezk kam es zu Separatismus, Dnipropetrowsk erklärte sich aufgrund des Einflusses des regionalen Oligarchen und Gouverneurs Kolomojskij mit der Ukraine loyal, und Charkiw, wo es sowohl Euromaidan- als auch Antimaidan-Proteste gab, blieb fest an der Seite der Ukraine, wobei die Loyalität mit dem Status quo ante auch hier auf Kolomojskijs Einfluss zurückgeht.

Kolomojskij und seiner Unternehmensgruppe Privat gebührt Dank dafür, dass sie eine Verbreitung des Separatismus nach Dnipropetrowsk und Charkiw verhindert haben, wobei das wohl hauptsächlich der Verteidigung finanzieller Interessen geschuldet und kein genuiner Ausdruck von Patriotismus war. Die Gründung und Finanzierung von verschiedenen Freiwilligenbataillonen, die an der Seite des Militärs in der Ostukraine kämpften, und die Kooptierung der ehemaligen Partei der Regionen in Charkiw, die die Unterstützung für die Föderalisierung schmälern sollte, machten Kolomojskij zum Major Player in der ukrainischen Politik, ohne dass er sich unmittelbar persönlich in ihr engagiert hätte.

Auf jeden Fall ging der russische Einfluss auf die ukrainische Politik drastisch zurück - er reduzierte sich auf einige Zirkel innerhalb des Oppositionsblocks und die in der Donbass-Region jeweils operierenden Separatisten. Die Krim und vor allem die sogenannten Volksrepubliken von Donezk und Luhansk als Geiseln zu nehmen, ist für Russlands Ziele viel nützlicher, als einfach weitere Territorien zu annektieren.

\section{Lokalwahlen}

Zur Zeit des Verfassens dieses Artikels gab es für einige Wahlkreise noch keine offiziellen Ergebnisse oder noch keinen Gewinner, weil eine zweite Runde noch nicht abgehalten wurde. Völlig klar ersichtlich ist jedoch, wie die Partei der Regionen und ihre Wählerschaft zerlegt 
wurden. In der östlichen und südlichen Ukraine wurde der Wahlkampf hauptsächlich zwischen vier Parteien ausgetragen, die mit Poroschenko, Kolomojskij oder Achmetow verbündet sind.

Obwohl er bei den Parlamentswahlen im letzten Jahr nur etwa zehn Prozent der Wählerstimmen erhalten hatte, schnitt der Oppositionsblock in der DonezkRegion, etwa in Slawjansk und Kramatorsk, und bei älteren Wählern gut ab, dominierte allerdings nicht. Der stärkste neue Herausforderer ist die Partei Nasch Krai (Unsere Region), ein Projekt von Präsident Petro Poroschenko, das verhindern sollte, dass der Oppositionsblock in den Regional- und Lokalparlamenten zu viele Mehrheiten gewinnt. Kern dieser Partei sind über 50 Bürgermeister, viele von der Partei der Regionen, die auf diese Weise versuchen, sich Unterstützung auf lokaler Ebene zu verschaffen. Die vorläufigen Ergebnisse zeigen, dass Nasch Krai die Fünfprozenthürde überwindet, sowohl im Stadtrat Charkiw als auch im Regionalparlament.

Der wirkliche Gewinner in Charkiw war jedoch der amtierende Bürgermeister Hennadij Kernes und seine neue, von Kolomojskij unterstützte Widrodschenja-Partei (Wiedergeburt). Obwohl Kernes ursprünglich an der Seite des Projekts Ukrainische Front zur Föderalisierung der Ost- und Südukraine angetreten war und trotz eines Mordanschlags auf und eines Gerichtsprozesses gegen ihn wurde er mit über 60 Prozent der Stimmen als Bürgermeister wiedergewählt. Widrodschenja scheint sowohl im Stadtrat Charkiw als auch im Regionalparlament eine absolute Mehrheit bekommen zu haben. Charkows Loyalität erhalten zu haben, ist ein wichtiger Sieg für Poroschenko, denn die zweitgrößte Stadt der Ukraine sollte Hauptstadt eines wie auch immer gearteten östlich-südlichen föderalen Gebildes werden, wie nach den Kongressen von 2004 und 2008 in Sewerodonezk (Luhansk) und von 2014 in Charkiw im Rahmen der sehr kurzlebigen Ukrainischen Front bekanntgegeben wurde.

Ein weiteres und das wohl wichtigste Projekt Kolomojskijs ist die Partei UKROP. Basierend auf der Unterstützung seiner Unternehmensgruppe Privat und der engen Verbündeten Hennadij Korban und Boris Filatow entwickelte sie sich im heimischen Dnipropetrowsk sehr gut. Die Bürgermeisterwahlen in Dnipropetrowsk gehen in eine zweite Runde, die zwischen Filatow und Oleksandr Wilkul vom Oppositionsblock ausgetragen wird; beide haben im ersten Wahlgang etwa 35 Prozent erreicht. UKROP ist bei den Einwohnern von Dnipropetrowsk und bei vielen Kriegsveteranen des Konflikts in der Ostukraine beliebt.

Nach dem sehr öffentlich ausgetragenen Konflikt zwischen Präsident Poroschenko und Kolomojskij wegen der Kontrolle des Letzteren über Ukrnafta sowie wegen Benzinlieferungen in die Konfliktzonen der Ostukraine und Korbans kürzlich stattgefundener Verhaftung hat der Präsident nicht mehr viele Freunde in Dnipropetrowsk. Es kann gut sein, dass diese Region erneut zu dem Kraftwerk der ukrainischen Politik wird, das es in den 1990er Jahren unter bemerkenswerten lokalen Persönlichkeiten wie Timoschenko und dem damaligen Ministerpräsidenten Pawlo Lasarenko gewesen ist.

\section{Statt das Blatt auszuwechseln werden die Karten neu gemischt}

Trotz Sieg des Euromaidan, neuem Präsidenten und neuer Regierung, Verlust der Krim und Kriegsausbruch im Donbass hat die ukrainische Innenpolitik keinen grundlegenden strukturellen Wandel erlebt. Noch immer lenken die Oligarchen das Spiel, und politische Parteien sind noch immer eine Fassade für ihre Interessen, es gibt nur momentan keine landesweite Struktur, die sie auf ihren Plätzen hält. Theoretisch ist die Entstehung einer neuen Art von subnationalem Autoritarismus möglich, diesmal in Dnipropetrowsk, auch wenn die Figur Kolomojskij dafür zu polarisierend ist und in der Ostukraine bei weitem nicht genug Unterstützung hat.

Eine Wiederholung der 1990er Jahre einschließlich eines Kampfs zwischen Dnipropetrowsk und den Zentralgewalten in Kiew findet in gewisser Weise schon statt, es gibt jedoch noch eine Opposition, sowohl gegenüber Kolomojskij als auch gegenüber Poroschenko. $\mathrm{Zu}$ ihr zählen einerseits diejenigen, die in der Ostukraine noch immer loyal zur Plattform der Partei der Regionen stehen, und andererseits die nationalistische Bewegung, die zwar in der Westukraine beliebter, im Osten dafür in einigen im Donbass kämpfenden Freiwilligenbataillonen stark vertreten ist. Bedenkt man zudem den sinkenden allgemeinen Lebensstandard, den Anstieg der Preise um 40 Prozent und die Abwertung der nationalen Währung um 250 Prozent, dann täte die Ukraine gut daran, den Teufelskreis der von Oligarchen bestimmten Politik zu durchbrechen.

Übersetzung aus dem Englischen: Sophie Hellgardt

Über den Autor

Mark Teramae ist Doktorand in Politikwissenschaft und Wissenschaftler am Aleksanteri-Institut an der Universität von Helsinki. 


\section{Steuern, Bruttoregionalprodukt der östlichen Regionen und Stimmen für Janukowitsch}

Grafik 1: Nettosteuerbewegungen in den drei östlichen Regionen im Jahr 2013, Milliarden Hrywnja

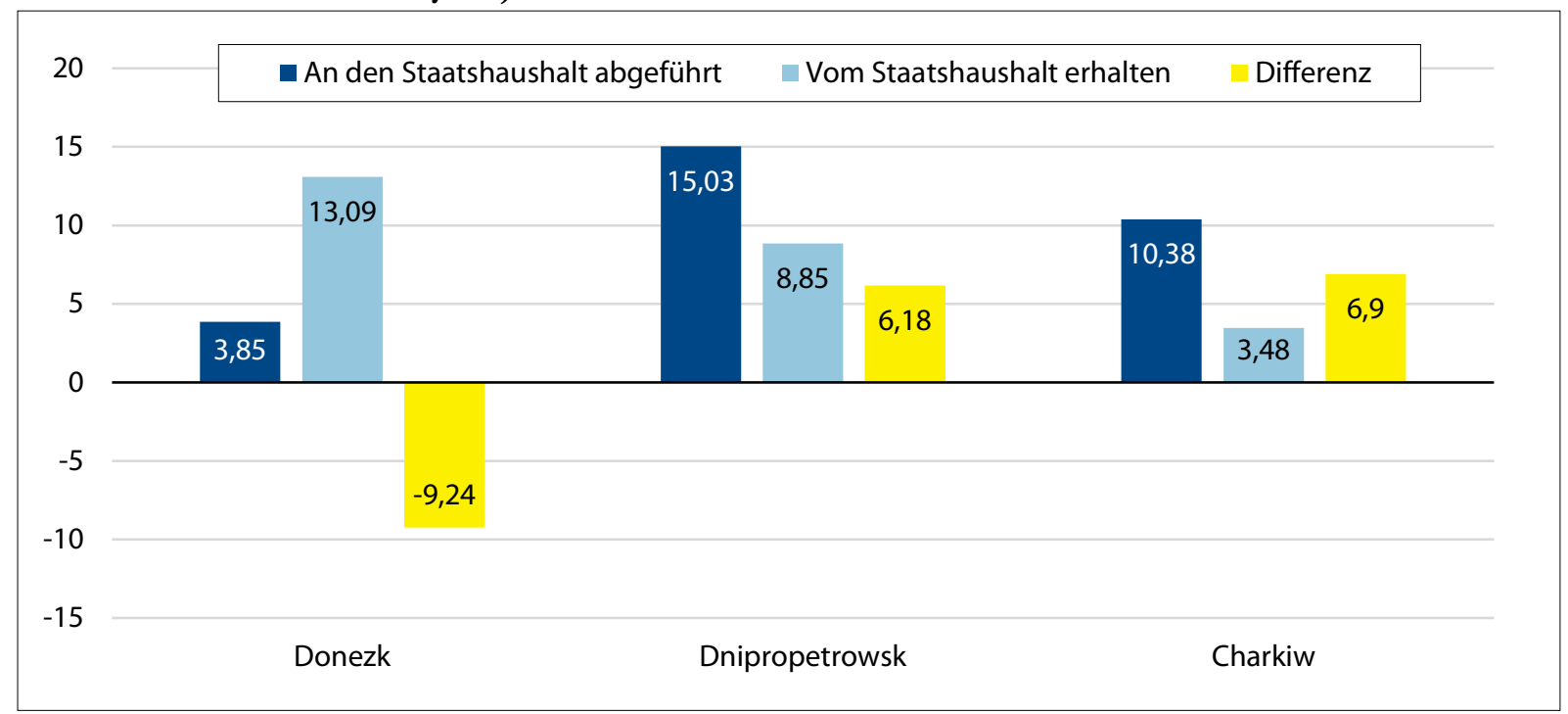

Steuern/Subventionen pro Kopf: Donezk: - >1.000 Hrywnja; Dnipropetrowsk: + >1.000 Hrywnja; Charkiw: + >1.000 Hrywnja Quelle: Mark Teramae; EconoMonitor, <http://www.economonitor.com/dolanecon/2014/05/05/ukraines-heavy-industry-glitte ring-prize-or-white-elephant/>

Grafik 2: Bruttoregionalprodukt pro Kopf der drei östlichen Regionen im Jahr 2013, Milliarden Hrywnja

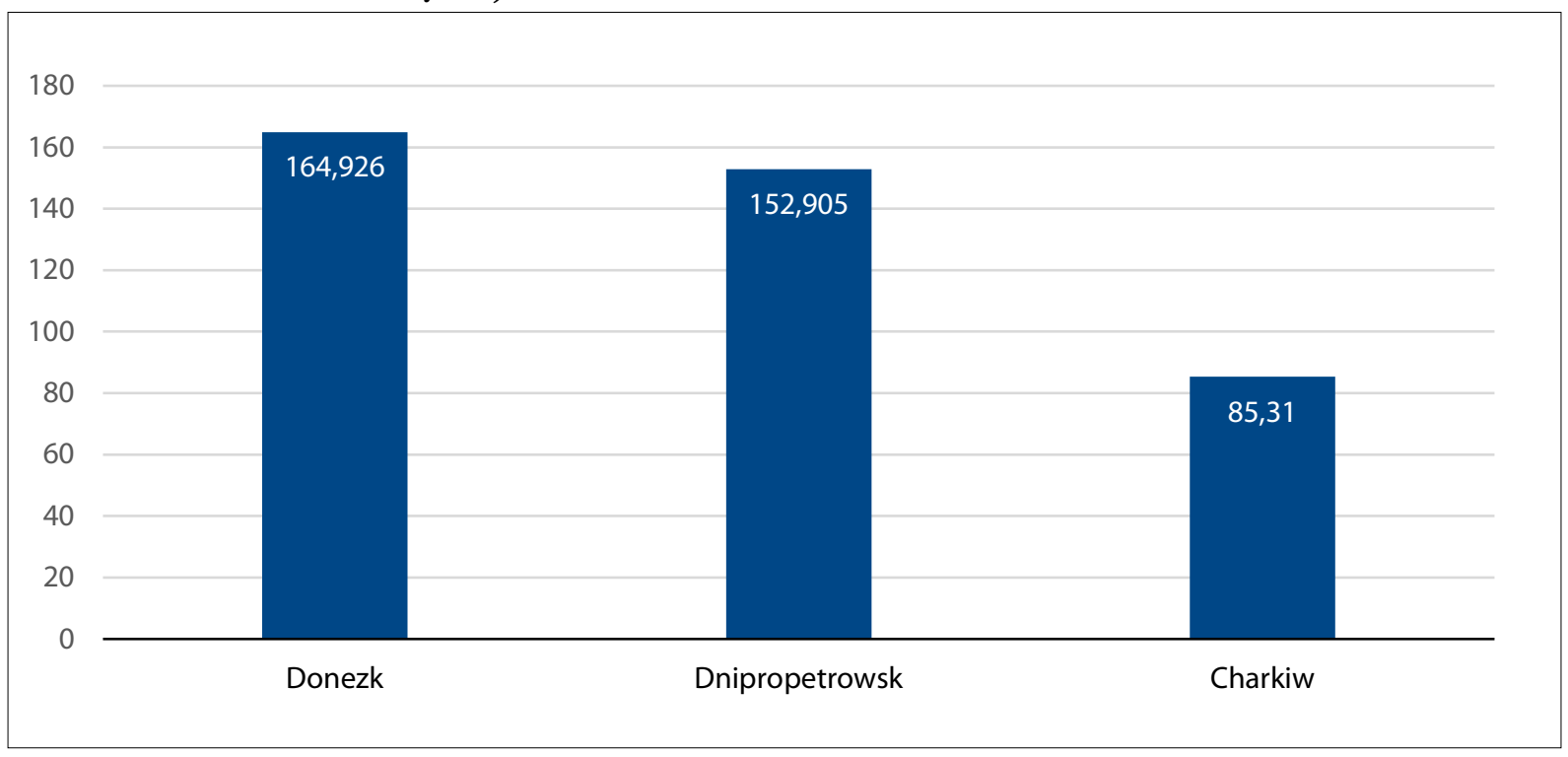

Quelle: Mark Teramae; StaatlicherStatistikdienst der Ukraine, <https://ukrstat.org/en/operativ/operativ2008/vvp/vrp/vrp2008_e.htm> 
Grafik 3: Stimmanteile für Wiktor Janukowitsch bei den Präsidentschaftswahlen von 2004 und 2010, \%

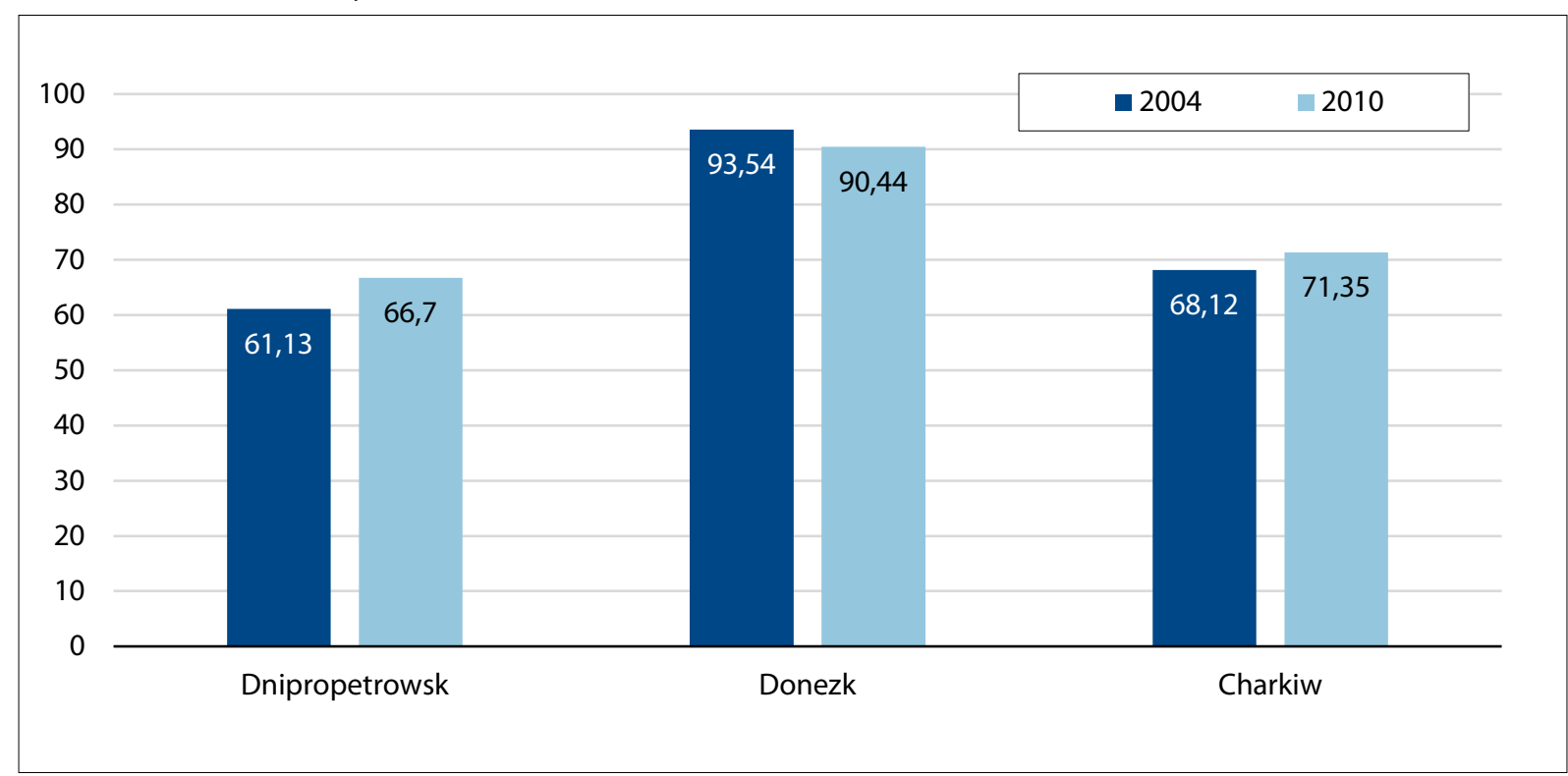

Quelle: Mark Teramae; Zentrale Wahlkommission der Ukraine, <http://cvk.gov.ua/>

Grafik 4: Stimmanteile für die Partei der Regionen und ihre Nachfolgepartei Oppositionsblock bei verschiedenen Parlamentswahlen, \%

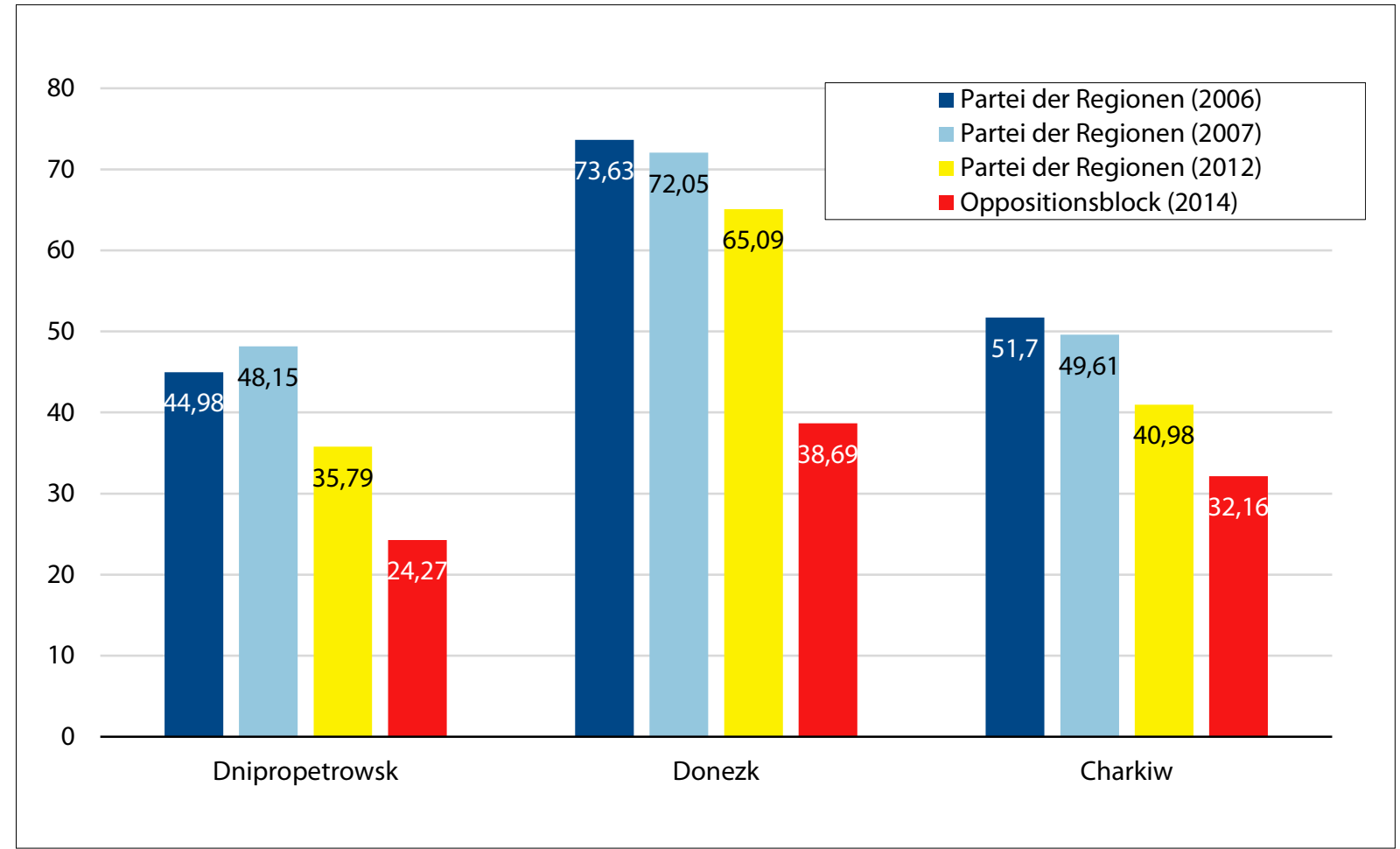

Quelle: Mark Teramae; Zentrale Wablkommission der Ukraine, <http://cvk.gov.ua/> 


\section{Die Lokalwahlen 2015 in Transkarpatien}

Von Oleg Friesen, München

\section{Zusammenfassung}

Die ukrainischen Lokalwahlen vom 25. Oktober 2015 fanden in der westukrainischen Region Transkarpatien vor dem Hintergrund des blutigen Zusammenstoßes von ukrainischen Sicherheitskräften und Kämpfern des Rechten Sektors statt. Wiktor Baloha ist die Führungsperson des Vereinten Zentrums, der stärksten Partei Transkarpatiens. Er unterstützt den Rechten Sektor und stellt sich somit gegen die ukrainische Regierung. Seit Ende der neunziger Jahre hat Wiktor Baloha seine Partei zur größten Regionalpartei der Ukraine ausgebaut und viele seiner Verwandten in politischen Führungspositionen untergebracht. Doch gelang es seiner Partei auch, eine Balance zwischen den ethnischen Gruppen Transkarpatiens zu errichten. Aus den Lokalwahlen in Transkarpatien ging das Vereinte Zentrum als Sieger hervor.

\section{Einleitung}

Am 25. Oktober wählten die Ukrainer ihre lokalen Verwaltungen. Die Resultate der Lokalwahlen, die als weiterer Test für die Demokratie in der Ukraine gelten, werfen die Frage auf, inwiefern sich das Land und speziell die einzelnen Regionen des Landes eineinhalb Jahre nach dem Maidan verändert haben. In der westukrainischen Region Transkarpatien fand die Wahl vor einem besonders schwierigen Hintergrund statt. Im Juli 2015 fand in der Stadt Mukatschewe eine Schießerei zwischen ukrainischen Sicherheitskräften und Kämpfern des Rechten Sektors statt, bei der drei Menschen zu Tode kamen. Dieser Zwischenfall führte die Machtlosigkeit der ukrainischen Regierung vor Augen, die es aus der Sicht vieler Bürger nicht vermag, bewaffnete paramilitärische Organisationen wie den Rechten Sektor zu kontrollieren und die Sicherheit in der Region zu garantieren. In der Hauptstadt des Nachbarstaates Ungarn verkündete der Chef des ungarischen Geheimdienstes daraufhin, seine Agenten würden in Transkarpatien für die Interessen Budapests eintreten und die in der Region ansässige ungarische Minderheit schützen. Derartige Aussagen eines hohen Staatsdieners führten prompt zu diplomatischen Verstimmungen zwischen der Ukraine und seinem westlichen Nachbarn Ungarn.

Der Zwischenfall in Mukatschewe führte aber auch zu Spannungen zwischen der Kiewer Regierung und der Partei Edynyj Zentr (Vereintes Zentrum), die seit ihrer Gründung im Jahr 2008 zur dominierenden politischen Kraft in Transkarpatien geworden ist. Die Führungsperson dieser Partei, Wiktor Baloha, ging mit seiner Aussage, den Rechten Sektor finanziell zu unterstützen, auf Konfrontationskurs zum vom Präsidenten eingesetzten Gouverneur Transkarpatiens Hennadij Moskal. Während das Vereinte Zentrum, die Partei von Wiktor Baloha, mit 22,79 Prozent wie erwartet stärkste Kraft im Regionalparlament Transkarpatiens wurde, sorgten die Wahlergebnisse auch für unvorhergesehene Überra- schungen. So verpasste der Kandidat der Präsidentenpartei Block Petro Poroschenko-Solidarität (BPP-Solidarität), der als Favorit für den Bürgermeisterposten der transkarpatischen Hauptstadt Uschhorod galt, den Einzug in die Stichwahl.

Die ukrainische Zivilgesellschaft beobachtete, wie sich die ehemaligen Mitglieder der sich nach dem Maidan im Auflösungsprozess befindenden Partei der Regionen (PdR) des Ex-Präsidenten Wiktor Janukowitsch bei den Lokalwahlen schlugen. Ukrainische Medien stellen den »Oppositionsblock«als Verlierer der Wahl dar. Die Nachfolgepartei der PdR konnte selbst in den ostukrainischen Wahlkreisen nur eine unter den Erwartungen liegende Anzahl von Mandaten erreichen, obwohl ihr lokaler Spitzenkandidat Oleksandr Wilkul in die am 14. November stattfindende Stichwahl für das Bürgermeisteramt der Millionenstadt Dnipropetrowsk einzog. Viele ehemalige Politiker der PdR gewannen als Mitglieder anderer Parteien Mandate. So wurde das ehemalige PdR-Mitglied Hennadij Kernes als Bürgermeister von Charkiw für die Partei Widrodzhennya (Wiedergeburt) wiedergewählt und eine Gruppe von ehemaligen PdR-Politikern gründete im Vorfeld der Lokalwahlen ein Netz von regional agierenden Parteien mit dem Namen Nasch Kraj (Unser Land), deren auf Stadtebene agierender Ableger Nasche Misto (Unsere Stadt) bei den Lokalwahlen zur stärksten Fraktion im Stadtrat der südwestukrainischen Regionshauptstadt Tscherniwzi wurde. Auch in der transkarpatischen Hauptstadt Uschhorod kann mit Bohdan Andriiw ein Kandidat von Wiedergeburt Bürgermeister werden, sollte er am 15. November die Stichwahl gewinnen. Der Ausgang der Lokalwahlen hat gezeigt, dass die Nachfolgeparteien der PdR in den westlichsten Regionen der Ukraine keinesfalls totgesagt werden dürfen und besonders für Angehörige ethnischer Minderheiten, für dessen Rechte sie einzutreten beanspruchen, eine große Rolle spielen. Doch auch die Führungsperson von Vereintes Zen- 
trum, Wiktor Baloha, hat eine mit der PdR verbundene Vergangenheit.

\section{Wiktor Baloha und Vereintes Zentrum}

Der politische Aufstieg Wiktor Balohas begann 1997 in der Vereinten Sozialdemokratischen Partei der Ukraine, die zu diesem Zeitpunkt von dem Oligarchen Wiktor Medwedtschuk geführt wurde und den damaligen ukrainischen Präsidenten Leonid Kutschma unterstützte. Als Mitglied dieser Partei wurde er 1998 Bürgermeister seiner Heimatstadt Mukatschewe und 1999 zum Gouverneur Transkarpatiens ernannt. Als Leonid Kutschma 2002 seinen damaligen Premierminister Wiktor Juschtschenko entließ, gab Baloha aus Protest gegen diesen Schritt sein Amt als Gouverneur auf und folgte Juschtschenko in dessen Partei Nascha Ukraina (Unsere Ukraine). Als er 2002 in die Werchowna Rada gewählt wurde, trat er Juschtschenkos Fraktion bei. Baloha engagierte sich für die Orangene Revolution und übernahm nach der Wahl Juschtschenkos zum Präsidenten die Leitung der Präsidentenkanzlei (2006-2009), nachdem er erneut für kurze Zeit Gouverneur Transkarpatiens gewesen war. 2009 zerstritt Baloha sich jedoch mit Juschtschenko und wechselte in die von ihm mitgegründete neue Partei Vereintes Zentrum. Der Wechsel in die Opposition brachte ihm das Amt des Katastrophenschutzministers der späteren Janukowitsch-Regierung ein. 2012 trat Wiktor Baloha auch von diesem Amt zurück, um sich seiner Tätigkeit als Parlamentsabgeordneter in der Werchowna Rada der Ukraine zu widmen. Dort unterstützte er seit November 2014 auch die proeuropäischen Proteste auf dem Maidan.

Seit ihrer Gründung hat die Partei Vereintes Zentrum in Transkarpatien eine starke Wählerbasis geschaffen, die auch viele für die Region markante kulturelle Gräben überwindet. Balohas Wähler scheinen ihm nicht nachzutragen, dass er seit der Präsidentschaft Kutschmas unter jedem ukrainischen Präsidenten hohe Regierungsposten besetzte. Wiktor Baloha selbst erklärte dazu, dass er stets die Interessen Transkarpatiens im Blick gehabt hätte und sich für ihre Durchsetzung auf die Linie keines Präsidenten einschwören lassen würde. Das Vereinte Zentrum versuchte zunächst, auch in den anderen Regionen der Ukraine Fuß zu fassen, erlangte aber außerhalb Transkarpatiens keine Bedeutung. Auffällig sind die familiären Beziehungen, die in Balohas Partei eine Rolle spielen. Nach den Parlamentswahlen von 2014 sitzen neben Wiktor Baloha dessen zwei Brüder, Pawlo und Iwan, als unabhängige Kandidaten für die Region Transkarpatien in der Werchowna Rada in Kiew. Das vierte von insgesamt sechs für die Region vorgesehenen Einzelmandaten gewann Wasyl Petyowka, der ebenfalls mit Wiktor Baloha verwandt ist. Auch in der transkarpatischen Lokalpolitik spielen Balohas Familienmitglieder eine Rolle. So ist Balohas Ehefrau Oksana Mitglied des Regionalparlaments Transkarpatiens und ihr gemeinsamer Sohn, der 27 Jahre alte Andriy Baloha, ist der in den Lokalwahlen gewählte neue Bürgermeister der transkarpatischen Großstadt Mukatschewe.

Wolodymyr Kulyk, Experte des I. F. Kuras-Instituts für Politische und Ethnische Studien, erklärt Balohas Erfolg damit, dass viele Bürger Transkarpatiens den populistisch auftretenden Baloha als einen Politiker ansähen, der ihnen zuhört und ihre Probleme offen ausspricht. Die Popularität des seit seiner Wahl in die Werchowna Rada in Kiew tätigen Wiktor Baloha färbe somit auch auf dessen in Transkarpatien tätige Familienmitglieder ab. Wiktor Baloha selbst ist in seinem transkarpatischen Wahlkreis durchaus präsent und gibt regelmäßig Stellungnahmen zu aktuellen politischen Problemen Transkarpatiens ab. Baloha verteidigte nach dem blutigen Zwischenfall in Mukatschewe im Juli den Rechten Sektor und warf der Regierung in Kiew vor, ihre schützende Hand über den Rada-Abgeordneten Michaylo Lanyo (PdR) zu halten. Vor dem Eintreffen der Sicherheitskräfte begannen die Ereignisse in Mukatschewe am 11. Juli nämlich mit einem Zusammenprall von Kämpfern des Rechten Sektors mit Zigarettenschmugglern, für die Michaylo Lanyo Pate gestanden haben soll. Der Rechte Sektor beansprucht für sich, gegen die mit der Politik verbundenen kriminellen Strukturen in der Region vorzugehen. Die Regierung in Kiew wirft dem Rechten Sektor dagegen vor, selbst die Kontrolle über den Zigarettenschmuggel in der Region Transkarpatien anzustreben. Nach den Ereignissen in Mukatschewe ernannte Präsident Petro Poroschenko Hennadij Moskal zum Gouverneur der Region Transkarpatien. Moskal war zuvor Gouverneur der ostukrainischen Region Luhansk gewesen, weshalb ihn Präsident Poroschenko als den richtigen Mann bezeichnete, um die Ordnung in dieser Region, die Poroschenko mit der Ostukraine verglich, wiederherzustellen. Mit seinem Vergleich zielte der ukrainische Präsident auf die ethnischen Minderheiten Transkarpatiens ab, deren Organisationen seit der Unabhängigkeit der Ukraine "separatistische Tendenzen« entwickelt haben und unter russischem Einfluss stehen sollen.

\section{Die Minderheiten Transkarpatiens - die Ungarn und das "politische Russinentum"} Zwölf Prozent der Bewohner Transkarpatiens haben sich in der letzten Volkszählung im Jahr 2001 als Ungarn bezeichnet. Unterschiedlichen Schätzungen zufolge sollen trotz der Abwanderung vieler ethnischer Ungarn in den ungarischen Staat noch immer bis zu 150.000 
Ungarn in Transkarpatien leben. Die Region hat eine lange mit Ungarn verbundene Geschichte, denn bis zur Auflösung Österreich-Ungarns 1918 gehörte Transkarpatien zum Königreich Ungarn.

Nach der Unabhängigkeit der Ukraine bildeten sich in der Region zwei ungarische Parteien heraus, deren bedeutendere die Partei der Ungarn der Ukraine ist. Sie wird oft beschuldigt, den rechten Parteien Ungarns Fidesz und Jobbik nahezustehen und von ihnen finanzielle Unterstützung zu erhalten. In Ungarn ist die Lage der ungarischen Minderheit in der Ukraine oft wichtiges Wahlkampfthema. Gerne präsentieren sich dort Repräsentanten rechter Parteien als Verteidiger der Ungarn Transkarpatiens und beklagen eine Benachteiligung dieser Minderheit in der Ukraine, die in dieser Form gar nicht besteht. In diesen Zusammenhang fallen die Aussagen des ungarischen Geheimdienstchefs über die Tätigkeit ungarischer Agenten in Transkarpatien. Für ungarische Politiker hat die Verteidigung der Rechte der Ungarn in der Ukraine den Hintergrund, dass ein großer Teil der ukrainischen Ungarn die doppelte Staatsbürgerschaft besitzt und somit auch in Ungarn wahlberechtigt ist. Viele Transkarpatier, die vielleicht nur im entfernten Sinne ungarischer Abstammung sind, besitzen zudem eine »Ungarnkarte«, die ihnen Visaerleichterungen für die Einreise nach Ungarn bietet.

Die zweite ungarische Partei Transkarpatiens ist die Demokratische Ungarische Partei der Ukraine und steht der Sozialistischen Partei Ungarns nahe. Unter Vermittlung des ungarischen Staates traten die beiden ungarischen Parteien der Ukraine gemeinsam bei den Lokalwahlen an. Obwohl besonders in den neunziger Jahren Forderungen nach einer ungarischen Autonomie in Transkarpatien laut wurden, geht von den Ungarn heute entgegen der Absicht der russischen Staatspresse, die eine vermeintliche Unterdrückung der ungarischen Minderheit in der Ukraine gerne als Sujet aufgreift, keine separatistische Gefahr aus. Laut Wolodymyr Oliinyk, dem Projektmanager des Auslandsbüros der Friedrich-Naumann-Stiftung in Kiew, werden die ungarischen Parteien nur in einzelnen Kreisen gewählt, in denen ethnische Ungarn die Mehrheit ausmachen. So wurde bei den Lokalwahlen 2015 der ungarische Bürgermeister der Stadt Berehowe mit 80 Prozent der Wählerstimmen wiedergewählt. In Berehowe bezeichnen sich über 50 Prozent der Einwohner als Ungarn. Seit dem ukrainischen Minderheitensprachengesetz von 2012, welches Minderheitensprachen in Kreisen und Regionen zur Amtssprache erhebt, in denen sie von über zehn Prozent der Bewohner gesprochen werden, sind viele Ortsbezeichnungen in Berehowe nur noch auf Ungarisch zu finden. In der gesamten Region spielen die ungarischen Parteien nur eine geringe Rolle. Auch das Ver- einte Zentrum wirbt um die Stimmen der ungarischen Minderheit. Baloha erklärte die Partei der Ungarn nach den Lokalwahlen zusammen mit Vaterland zur einzigen Partei, mit der er sich eine Regierungskoalition in der Region vorstellen könne. Mit dem ungarischstämmigen Zoltan Lengyel stellte das Vereinte Zentrum ab 2008 den Bürgermeister von Mukatschewe, der bei den letzten Lokalwahlen den Weg für die Kandidatur von Andriy Baloha, dem Sohn Wiktor Balohas, freimachte.

Wiktor Baloha ist es ebenfalls gelungen, einen Teil der sogenannten russinischen Bewegung Transkarpatiens für sich zu gewinnen. Seit der Unabhängigkeit der Ukraine ist ein Streit darüber entbrannt, ob es sich bei den Russinen um eine eigenständige ethnische Gruppe oder eine Subethnie der Ukrainer, ähnlich den Huzulen und Lemken, handelt. Die tatsächliche Zahl der Russinen in Transkarpatien ist nicht bekannt. In der Volkszählung von 2001 wurden die Russinen zu den Ukrainern gezählt. Allerdings gehen Schätzungen von rund 10.000 Menschen aus, die sich nur als Russinen bezeichnen und sich somit von den Ukrainern abgrenzen. Laut Wolodymyr Kulyk von der Ukrainischen Akademie der Wissenschaften verstehen sich die meisten Russinen selbst als Subethnie der Ukrainer. Der Eindruck, dass es sich bei den russinischen Organisationen um eine organisierte nationale Bewegung handle, entstehe nur durch die Darstellung der Russinen in der russischen Propaganda und durch skandalöse Kommentare einzelner russinischer Politiker. Separatistische Tendenzen unter den Russinen sind Kulyks Aussage zufolge Einzelerscheinungen.

Russland unterstützt eine Reihe russinischer Organisationen finanziell, weshalb einzelne russinische Organisationen auch betont prorussisch auftreten. Der derzeit im Moskauer Exil lebende und in russischen Medien regelmäßig als Ukraine-Kommentator erscheinende Petro Hetzko bezeichnet sich als Führer der russinischen nationalen Bewegung und ging nach dem Maidan so weit, beim Kreml um die Entsendung von »Friedenstruppen« in die Ukraine zu ersuchen. Russische Medien nahmen den russinischen "Freiheitskampf « und seine „Unterdrückung« durch die ukrainische Regierung mit Freude in ihre Berichterstattung auf. Dabei wurde die Tatsache verschwiegen, dass sogar unter den russinischen Organisationen, die eine Anerkennung als ethnische Minderheit fordern, 90 Prozent Mitglieder des Dachverbands Nationale Russinische Rada sind, der sich klar proukrainisch und proeuropäisch positioniert. Der Vorsitzende dieses Dachverbandes, Yewhen Schupan, ist zudem Mitglied der Partei Vereintes Zentrum. Wolodymyr Oliinyk von der Friedrich-Naumann-Stiftung spricht von einem "politischen Russinentum«. Der Name Russine ist gleichbedeutend mit der deutschen 
Bezeichnung Ruthene. Die Ursprünge dieses Wortes liegen in der mittelalterlichen Kiewer Rus. Vom Mittelalter bis zum Ende der Habsburgermonarchie 1918 wurden alle (West-)Ukrainer als Ruthenen bezeichnet. Sich mit dem Namen Ruthenen von den Ukrainern abzugrenzen, ist also laut Oliinyk unmöglich. Der einflussreiche transkarpatische Politiker Wiktor Baloha verurteilt die separatistischen Tendenzen einiger vereinzelter russinischer Organisationen, unterstützt jedoch die Idee der Anerkennung der Russinen als eigenständige Ethnie innerhalb der ukrainischen Nation. Baloha deutete mehrmals an, womöglich selbst russinischer Abstammung zu sein, positionierte sich jedoch niemals klar.

Nach der Eingliederung Transkarpatiens in die UdSSR 1944 wanderten viele russischsprachige Bürger aus dem gesamten Gebiet der Sowjetunion nach Transkarpatien ein. Nach der Volkszählung von 2001 gaben 2,5 Prozent der Bewohner Transkarpatiens an, Russen zu sein. Trotz der regional geringen Anzahl ethnischer Russen fungiert Russisch als Sprache zwischenkultureller Kommunikation, denn viele ethnische Ungarn haben in den sowjetischen Schulen Russisch statt Ukrainisch gelernt. Nachdem Präsident Juschtschenko den obligatorischen Unterricht in ukrainischer Sprache einführte, kam es zu Protesten in der Region. Diese Proteste galten weniger der Tatsache, auf Ukrainisch unterrichtet zu werden, als der Umsetzung der Reform: Aus ungarischen Elternhäusern kommende Schüler bekamen denselben Lehrplan wie Schüler anderer Regionen der Ukraine, der muttersprachliche Kenntnisse der ukrainischen Sprache voraussetzt. Der Widerstand gegen die von Juschtschenko verordnete Sprachenpolitik brachte der Partei der Regionen bei den Präsidentschaftswahlen 2010 viele Stimmen aus Transkarpatien ein. Die Partei Wiedergeburt, die zum Großteil aus ehemaligen PdRMitgliedern besteht, ist bei den aktuellen Lokalwahlen mit 12,85 Prozent nach dem Vereinten Zentrum und dem Block Petro Poroschenko drittstärkste Kraft des transkarpatischen Regionalparlaments geworden. In Uschhorod, der Hauptstadt der Region Transkarpatien, verpasste der BPP-Kandidat den Einzug in die Stichwahl, die am 15. November zwischen dem Spitzenkandidaten der Wiedergeburt Andriiw und einem Parteilosen ausgefochten wird, der im Laufe seiner politischen Karriere durch antisemitische Kommentare über den ukrainischen Premierminister Arsenij Jazeniuk aufgefallen ist.

\section{Fazit}

Die Lokalwahlen in Transkarpatien haben die politischen Machtverhältnisse in der Region nicht verschoben. Das Vereinte Zentrum hat die Region weiterhin im Griff und gilt als Partei der Balance zwischen den verschiedenen ethnischen Gruppen Transkarpatiens, wenn nicht gar als Garant gegen Separatismus unter ihnen. Mit seiner Unterstützung des Rechten Sektors hat Baloha klar Partei gegen die Regierung in Kiew ergriffen. Anders als in Transkarpatien sind Balohas politische Verbündete in der gesamten Ukraine jedoch rar, denn auch führende Köpfe des Rechten Sektors wollen nicht mit einem Politiker assoziiert werden, der bereits unter drei ukrainischen Präsidenten unterschiedlicher Ausrichtungen Karriere gemacht hat und zudem seine Familienmitglieder in Spitzenpositionen der Partei unterbringt. Auch die ehemaligen Mitglieder der Partei der Regionen spielen weiterhin eine Rolle in Transkarpatien. So bleibt der in den blutigen Zwischenfall von Mukatschewe verwickelte Michaylo Lanyo weiterhin Abgeordneter der Werchowna Rada der Ukraine. Michaylos Bruder, Iwan Lanyo, gewann bei den Lokalwahlen den Posten des Bürgermeisters der transkarpatischen Kurstadt Swalyawa.

Über den Autor

Oleg Friesen ist Masterstudent der Osteuropawissenschaften an der LMU München und war im Juni und Juli 2014 sowie von März bis Juni 2015 Praktikant im Auslandsbüro der Friedrich-Naumann-Stiftung in Kiew. 


\section{Die Resultate der Lokalwahlen 2015 für das transkarpatische Regionalparlament}

Grafik 1: Die Stimmenanteile der Parteien nach den Wahlen 2015 zum transkarpatischen Regionalparlament, \%

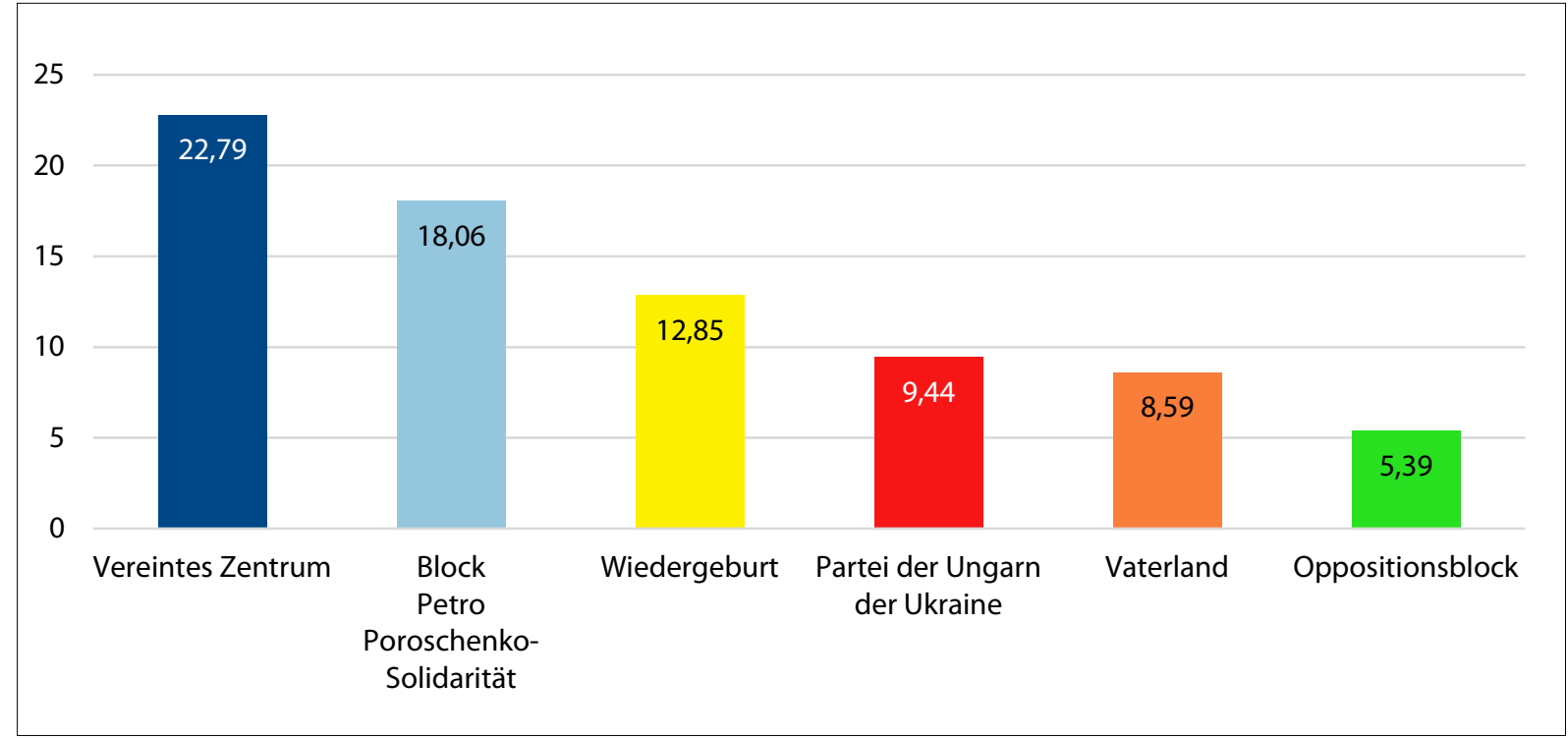

Quelle: Oleg Friesen nach Angaben von <pmg.ua>

Grafik 2: Die Zusammensetzung des transkarpatischen Regionalparlaments nach den Lokalwahlen 2015, Mandate

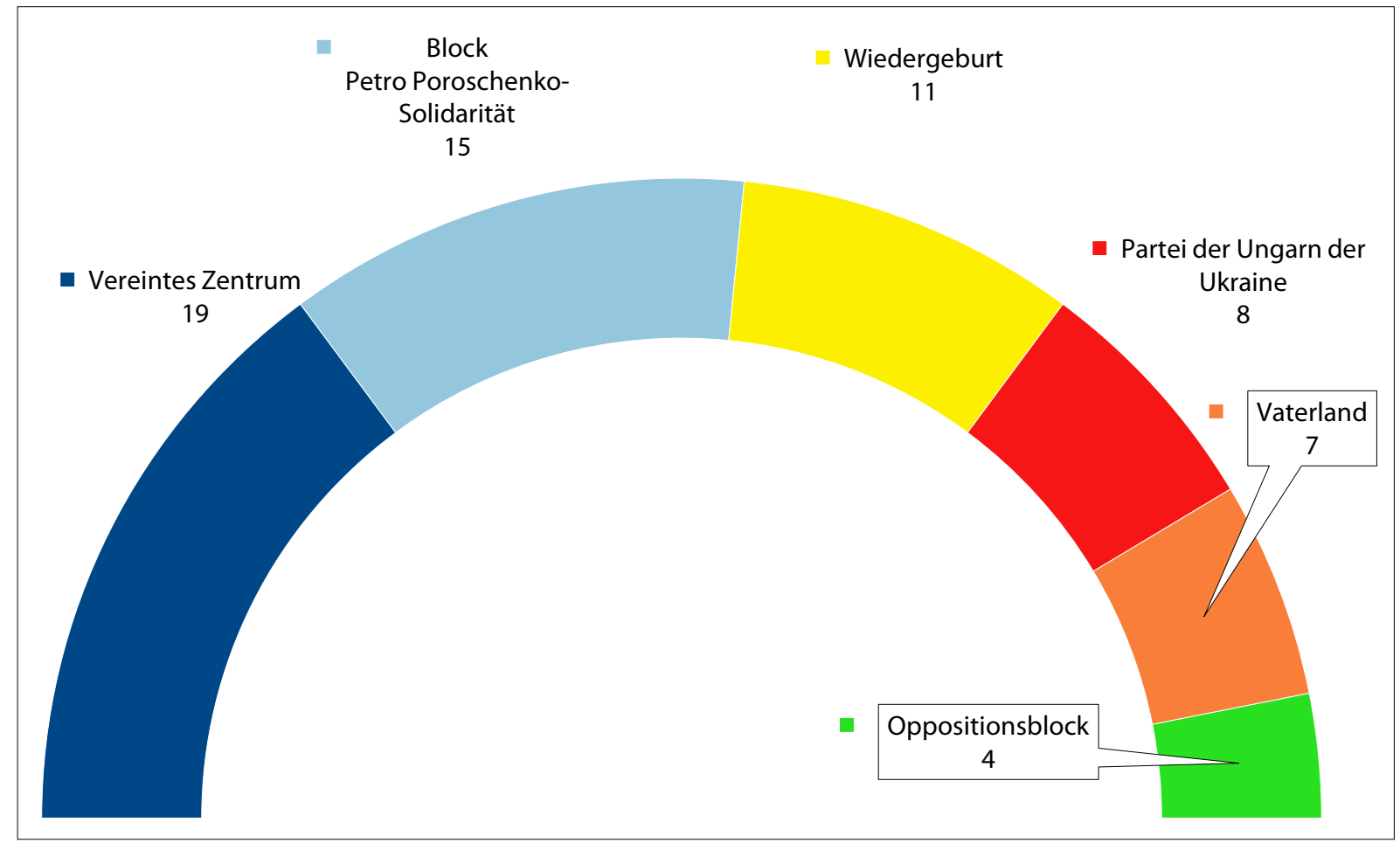

Quelle: Oleg Friesen nach Angaben von <pmg.ua> 


\title{
Auszüge aus der Erklärung der internationalen Wahlbeobachter-Mission (IOEM)
}

\author{
INTERNATIONAL ELECTION OBSERVATIONMISSION (IEOM): Statement of \\ Preliminary Findings and Conclusions (Ukraine- Local Elections, 25 October 2015)
}

Kyiv, 26 October 2015-This Statement of Preliminary Findings and Conclusions is the result of a common endeavour involving the OSCE Office for Democratic Institutions and Human Rights (OSCE/ODIHR), the Congress of Local and Regional Authorities of the Council of Europe (Congress) and the European Parliament (EP).

(...) The assessment was made to determine whether the election complied with OSCE commitments and Council of Europe standards, as well as international obligations and domestic legislation. Each of the institutions involved in this IEOM has endorsed the 2005 Declaration of Principles for International Election Observation. This Statement of Preliminary Findings and Conclusions is delivered prior to the completion of the election process. The final assessment of the election will depend, in part, on the conduct of the remaining stages of the election process, including the tabulation of results and the handling of possible post-election day complaints and appeals. The OSCE/ODIHR EOM will maintain a presence in Ukraine for observation of the foreseen second rounds of mayoral elections. The OSCE/ODIHR will issue a comprehensive final report, including recommendations for potential improvements, some eight weeks after the completion of the election process. The Congress final report will be adopted at the next plenary session in March 2016. The EP will present its report at an upcoming meeting of the Committee on Foreign Affairs.

\section{PRELIMINARY CONCLUSIONS}

The 2015 local elections were widely viewed as a barometer of the authorities' intentions to maintain the positive standards achieved during the 2014 presidential and parliamentary elections. The elections were competitive, well organized overall and the campaign generally showed respect for the democratic process. Nevertheless, the complexity of the legal framework, the dominance of powerful economic groups over the electoral process, and the fact that virtually all campaign coverage in the media was paid for, underscore the need for continued reform. Additional efforts are needed to further enhance the integrity of and public confidence in the electoral process. The voting and counting process was transparent and orderly overall, despite the lack of clarity in the procedural provisions.

The elections took place in challenging political, economic, humanitarian and security environment, and against the backdrop of a constitutional reform process aiming at decentralization. The context was characterized by the illegal annexation of the Crimean peninsula by the Russian Federation and the temporary control of parts of the territory of the Donetsk and Luhansk oblasts by illegal armed groups. This made it impossible for over 5 million voters in these areas to vote. The Central Election Commission (CEC) made resolute efforts to organize elections throughout the country, but they could not be held in parts of Donetsk and Luhansk oblasts and on the Crimean peninsula.

The election law was adopted less than four months before election day in an non-inclusive manner. Despite longstanding OSCE/ODIHR and the Council of Europe's Venice Commission recommendations, the legal framework continues to be fragmented, contains gaps and ambiguities and lacks clarity. Overall, the legal framework falls short of some OSCE and Council of Europe commitments and international standards.

The CEC operated collegially overall, meeting legal deadlines. Cases of decisions along political lines, of evasion of open discussion during sessions, of arbitrary decision-making, as well as abuse of authority by some Territorial Election Commissions (TECs), undermined confidence in these commissions. The complexity of the election law raised concerns among the commissioners and affected their performance. A number of interlocutors voiced allegations of corrupt practices related to the trading of seats in the Precinct Election Commissions (PECs).

OSCE/ODIHR EOM interlocutors expressed general trust in the voter registration system. Voters who were away from their voting addresses on election day were not able to cast their ballots, except for those voting in special election precincts established in medical institutions. The law does not provide for voting by internally displaced persons (IDPs).

The restrictive interpretation and inconsistent implementation of candidate registration rules hindered the right for candidates to stand on an equal basis in several instances, contrary to OSCE and Council of Europe commitments and other international obligations and standards. These problems persisted throughout the pre-election period, affecting the equal opportunity to campaign. In a number of instances observed by OSCE/ODIHR EOM, TEC decisions with respect to the registration of certain candidates and party lists appeared politically motivated and designed to 
exclude certain political forces from participating in the elections. Often the CEC and the courts intervened to restore the rights of candidates.

The campaign environment was competitive and voters had a wide array of parties and candidates to choose from. However, it was dominated by wealthy donors and their associated business interests who focused their resources on the mayoral and oblast council races. The absence of ceilings on campaign expenditures further prevented the level playing field during the campaign period. Campaign finance regulations remained insufficiently transparent. The OSCE/ ODIHR EOM received widespread allegations of vote-buying. In some areas the campaign was marred by threats and physical attacks targeting candidates and campaign workers.

The media sector with its vividness and turmoil reflects Ukraine's overall political climate. The growing power and politicization of media groups affect both national and regional media. The political and business interests controlling the media often influence editorial policy, and the malpractice of paid-for journalism is widespread. The legal framework overregulates pre-election coverage, yet poorly defines provisions for it, at odds with OSCE commitments and international standards. The halting and incomplete transformation of the National Television and Radio Company (NTRC) from a state-owned to a public broadcaster hampered independence and editorial freedom of the NTRC called for by international obligations. OSCE/ODIHR EOM media monitoring showed that only three registered parties were granted meaningful editorial coverage across the media landscape. Most of the monitored TV channels with a nationwide reach, including the NTRC, predominantly featured two to three political parties each within their prime time programming.

National minorities' participation in these elections was affected by the crisis in the east and the temporary control of parts of the territory by illegal armed groups, and the illegal annexation of the Crimean peninsula. Representation of national minorities was further hindered by several aspects of the election legislation, especially the inability to selfnominate or run independently in local council races, as well as the increased five per cent threshold for party lists.

Most complaints filed with the CEC were considered in private by individual CEC members, which undermined the transparency and collegiality of the process. Courts handled complaints and appeals within the established timelines respecting due process. However, non-uniform interpretation of the law undermined legal certainty, as well as the principle of equality before the law.

Citizen observer groups and international organizations could register an unlimited number of observers who have broad rights, including the right to attend sessions of all election commissions and to receive documents, including results protocols. The inclusive accreditation of observers contributed to the transparency of the electoral process.

For the first time, the election law introduced the requirement of at least 30 per cent representation of each gender on a party list, but regrettably did not provide for any sanctions for failure to comply. According to the CEC, women comprised about 35 per cent of all registered candidates for the proportional races and 13 per cent in mayoral races. However, female candidates were largely absent from the media landscape, and a small number of them featured in the campaign across the country. Women are well-represented at the CEC and on the TECs, including in leadership roles.

The voting and counting process was transparent and orderly overall. Printing and distribution of ballots proved problematic in many parts of the country. Despite the lack of clarity in the procedural provisions, the PECs were generally able to organize the voting and counting well. Tabulation was ongoing at the time of publication. Party and candidate agents were present in large numbers during all stages of the process, while citizen observers were noted less frequently. (...)

Quelle: <http://www.osce.org/odihr/elections/ukraine/194406?download=true>

\title{
Auszüge aus der Erklärung des ukrainischen Bürgernetzes OPORA
}

\author{
Statement on Interim Observation Results of 2015 Regular Local Elections \\ Local elections in Ukraine were held with numerous violations of the electoral process organization procedure and inter- \\ national standards including Main drawbacks concerned instable electoral legislation and vague procedures, violation of \\ equal opportunities principle and the principle of balanced proportion of mandates, low level of ballot papers security and \\ violations which may be specified and voter bribery. However, Civil Network OPORA affirms that election day violations \\ were usually unsystematic and didn't have significant influence on election results or vote count process, and the cam-
}


paign itself was quite competitive. Final summary on regular local elections will be published by Civil Network OPORA only after territorial election commissions finish all the procedural activities and official election results are announced.

However, the fact that politically motivated but not legal grounds were used to stop the voting process in Mariupol and Krasnoarmiisk can be interpreted as obstruction to realization of citizen voting rights and the right to local self-government. Thus, these facts must be assessed by the Central Election Commission and law-enforcement bodies of Ukraine in an independent and unbiased manner.

OPORA's summary is based on the results of long- and short-term observation, criteria and principles of democratic elections established by documents of the Venice Commission, Copenhagen Conference, and the Organization for Security and Co-operation in Europe (OSCE).

Summary on the course of election campaign from Civil Network OPORA:

- Systematic problems emerged in application of the new Law on Local Elections due to the non-inclusive approach to its drafting and instability of electoral legislation as a whole. Some regulations of the Law were either declarative or didn't provide specific requirements to the procedures and, therefore, became a proof that legal framework was not prepared in proper way. The Central Election Commission sometimes even had to not only provide explanations on the certain law regulations, but also, in fact, take upon itself legislative functions of the parliament. For example, a situation with gender quotas in electoral lists of political parties, or a procedure of mandate distribution with consideration of the "first candidate in a list", which wasn't specifically defined by the legislation;

- Registration of candidates and party lists wasn't finished before the deadline established by the law in the certain communities and, therefore, opportunities of candidates for a comprehensive campaign were limited;

- Both parties/candidates electoral subjects and territorial election commissions failed to secure the transparency and accountability of campaign financing at an adequate level. Early campaigning before official registration of candidates was financed with violation of legislative requirements and systematical. The access to information about interim reports on campaign fund expenses wasn't secured in a way that the voters and NGOs could have had quick access to these data.

- Voter bribery incidents occurred in different regions of Ukraine, resulting from the fact that the certainty of punishment principle doesn't work in such cases and judiciary practices prove to be inefficient. However, law enforcement bodies are more active if compared to 2012 and 2014 parliamentary elections and 2010 local elections, and duly respond to requests of OPORA's observers. However, we will be able to assess the efficiency of investigations into this category of violations on the basis of court practices only after six months after the election campaign finishes.

- The scale of centralized misuse of administrative resources was much smaller if compared to 2010 elections, and it didn't have a systematic influence on the election process.

- There were many situations hazarding the election process itself if we mention about production of ballot papers. For example, approved forms with errors and inaccuracies or dubious interpretation of the law in regard to contracts with printing houses. As a result, ballot papers were considered inappropriate, additional expenses were made $(\ldots)$ to print new ballots, or even the voting itself was canceled.

The final report on observation results containing detailed findings of the Civil Network OPORA are going to be published in a few weeks. OPORA will also include recommendations for improvement of electoral process in this report. Civil Network OPORA conducts citizen observation of local elections in Ukraine, scheduled for 25 October 2015. Civic monitoring conducted by OPORA-is a type of network activity, aimed at impartial assessment of the preparation and conduct of elections, as well as preventing electoral violations through comprehensive civic action. 144 long-term observers were deployed to all Ukrainian regions on 5 September, and 3000 short-term observers will join them on the election day. Quelle: <http://www.oporaua.org/en/news/9864-zajava-shchodo-promizhnyh-rezultativ-sposterezhennja-za-chergovymy-miscev ymy-vyboramy-2015-roku>

\section{Die Rede von Präsident Poroschenko zu den Lokalwahlen 2015}

President's address on local elections (30.10.2015)

Fellow Ukrainians!

Local elections held on Sunday have completed the restart of the government initiated last year. First of all, I would like to thank everyone for coming to the polling stations and demonstrating concern for the future of the country. 
Although, amendments to the Constitution regarding decentralization have been adopted only in the first reading, we have broadened financial opportunities of local self-government approximately by $40 \%$ through amendments to the Budget and Tax Codes. That is why you have chosen not simply "assessors", but full-fledged representatives that gained real opportunities to solve local problems and responsibility.

The election campaign was characterized by a high level of competition, great number of participants and active campaigning.

Certain election commissions, unfortunately, dared violate the law or demonstrated insufficient professionalism. In such exceptional cases, as guarantor of the Constitution, rights and freedoms of citizens, I had to influence the situation, whether it was Mariupol or Pavlohrad.

Certainly, there was still an acute problem of vote-buying by individual candidates, but this time law enforcement bodies provided active reaction to that.

In general, violations were mostly of technical, organizational and procedural nature. According to non-governmental monitoring organizations and a great number of foreign observers, these violations did not influence the results.

Representatives of authoritative international organizations, which have been specially invited to get independent and objective evaluation of the quality of local elections, described them as positive. According to the envoys of the OSCE, Council of Europe, European Parliament, European countries, the elections were free and fair, and met the international standards and European political culture.

These elections have brought us closer to Europe and demonstrated the irreversibility of changes in the country, maturity of society and proper attitude of authorities to democratic procedures.

The number of political parties that will be represented in local councils is much greater than the number of parties represented in the Parliament. More than 20 participants crossed the five percent barrier.

However, the most important thing is that the revenge of anti-Ukrainian forces has not taken place. And it is due to your wisdom, dear Ukrainians!

Political forces of the ruling coalition have gained a decent result. Overall support for pro-European and proUkrainian forces is much bigger than that of the party originating from Yanukovych's Party of Regions.

In the nearest time, I expect local councils of all levels to form pro-Ukrainian majority capable of adopting efficient decisions and solving problems of local communities.

Emotions in the parliamentary coalition should also fade out promptly. Competition of its members in the local elections has become a real challenge for the coalition.

I call on everyone to bury the hatchet, smoke the pipe of peace and make up for the lag in the pace of reforms.

On the next plenary week, the Parliament should adopt a series of draft law required for the fulfillment of technical conditions by Ukraine for establishing the visa-free regime with the European Union.

Immediately after announcement of election results, I expect proposals from the parliamentary factions regarding the new composition of the Central Election Commission. It is the issue of our agenda.

Once again, I urge all the parties to refrain from crossing the red lines in political competition. Otherwise, the political struggle may become extremely tense and reduce country's capabilities of confronting external threats.

Fellow Ukrainians!

It is important that the vote took place in the territory of Donbas controlled by Ukraine.

It is the first time when Donetsk and Luhansk regions elected local authorities on a relatively competitive basis. This has never happened there before.

The monopoly of famous political force, which has been forming there for ages, has been ruined for the first time.

Pro-European parties will be represented in the councils of Donetsk and Luhansk regions for the first time. Even more so, they are obliged to coordinate efforts on the control over the activities of local majority.

Dear Ukrainians!

Those who think they are still in 2004 are wrong. The country has changed and Donbas has changed. It is no longer one's patrimony. Unfortunately, because of the irresponsibility of a well-known political force, elections in Mariupol were disrupted.

I expect the Parliament to make respective amendments to the law in order to ensure immediate elections in Mariupol.

Fellow Ukrainians!

The elections are held in conditions of severe social crisis. Kremlin military aggression against Ukraine and economic war, in which Russia has almost completely closed market for Ukrainian goods, dealt a powerful blow at the economy and living standards of Ukrainians.

I would like to express gratitude to those who objectively looked at this issue, who appreciated our efforts aimed to establish a truce at the front and macro-financial stability in the rear. 
My political party confirmed the status of a national party that unites the country. Not for nothing is it called "Solidarity". As of today, the party gained the first place in the elections in Kyiv and 14 regional councils from 23 regions where elections were held; in seven regions, the party was the second to reach the finish line. In addition, "Solidarity" will be represented in all district councils of Donbas controlled by Ukraine.

This result is not a reason to celebrate. It implies increased responsibility of the party and me personally. The government in general and I personally are making adequate and self-critical conclusions from the results of the elections.

We see that people demand serious work on mistakes and acceleration of reforms.

And we will act in accordance with this guideline.

Glory to Ukraine!

Quelle: <http://www.president.gov.ua/en/news/zvernennya-prezidenta-ukrayini-shodo-viboriv-do-organiv-misc-36238>

DOKUMENTATION

\section{Die vorläufigen Ergebnisse der Lokalwahlen 2015}

\section{Grafik 1: Anzahl der Abgeordnetenmandate in den Gemeinderäten nach Verwaltungseinhei- ten bei den Lokalwahlen 2015 und 2010}

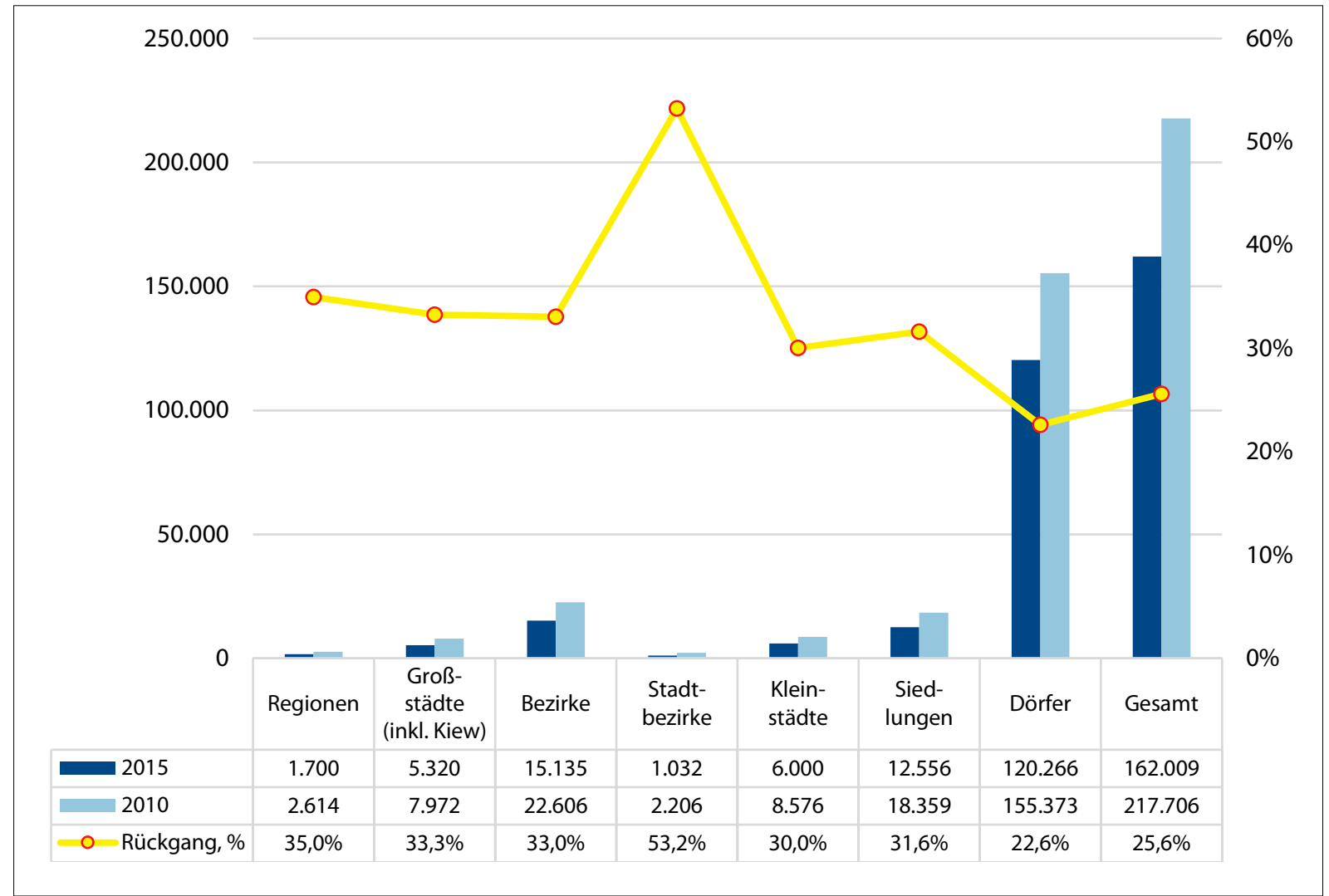

Anmerkung: 2015 wurden manche Gemeinden vergrößert. Die Zentrale Wablkommission der Ukraine gibt die Zablen für die Gemeinden, in denen die Wahlen turnusmäßig und erstmalig stattgefunden haben, gesondert an. Hier sind die Gesamtzahlen angegeben. Die Krim ist nicht mit eingerechnet, sowohl für 2010 als auch für 2015. Aufgrund des Konflikts im Donbass wurden die Wablen nur in Gemeinden durchgeführt, die von der ukrainischen Regierung kontrolliert werden.

Quelle: Zentrale Wahlkommission der Ukraine, <http://www.cvk.gov.ua/wvm2015/pvm003pt001f01=100pt00_t001f01=100.html>, <http://www.cvk.gov.ua/wvm2015/pvm002pt001f01=101pt00_t001f01=100.html> und Berechnungen der Redaktionder Ukraine-Analysen. 
Grafik 2: Anzahl der Bürgermeister, Siedlungs- und Dorfvorsteherposten nach Verwaltungseinheiten bei den Lokalwahlen 2015 und 2010

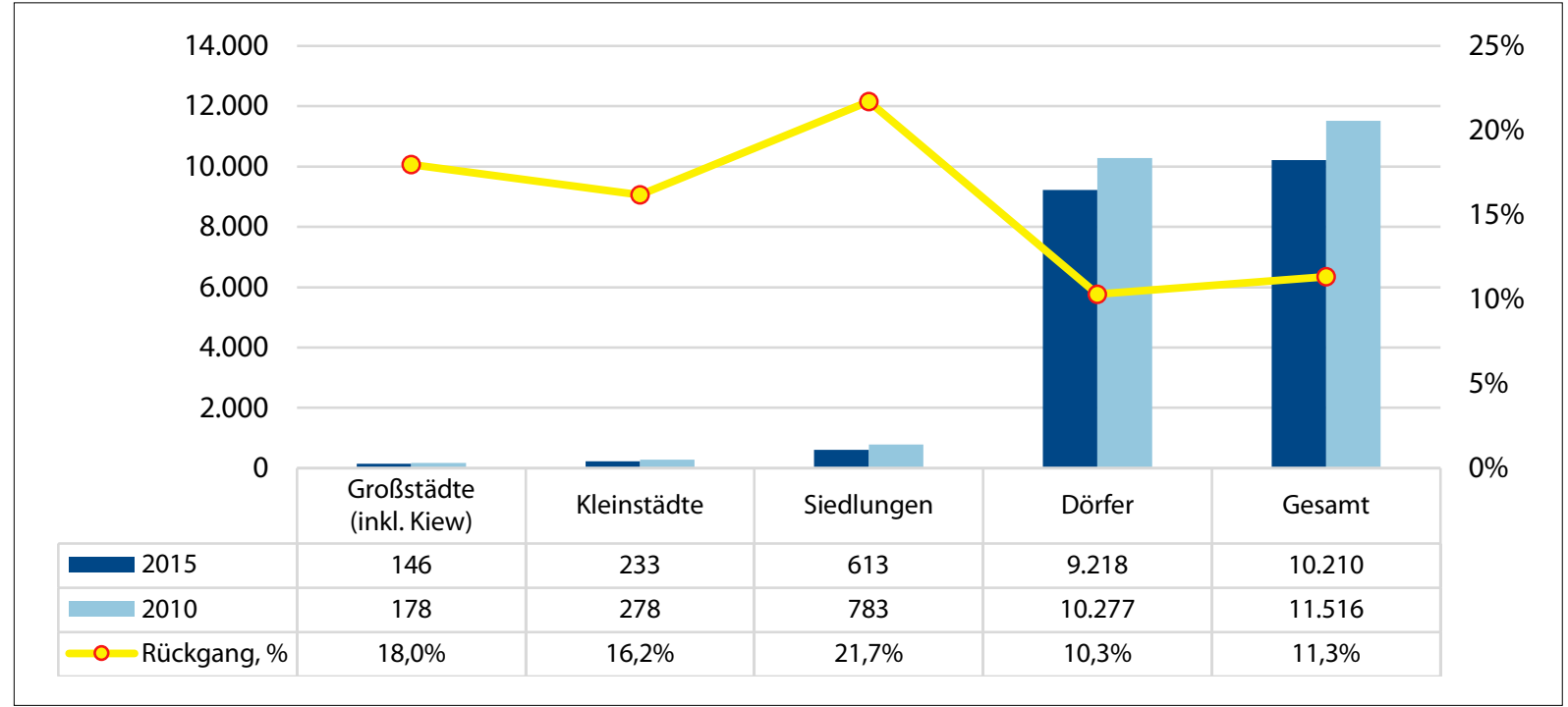

Anmerkung: 2015 wurden manche Gemeinden vergrößert. Die Zentrale Wablkommission der Ukraine gibt die Zahlen für die Gemeinden, in denen die Wablen turnusmäßig und erstmalig stattgefunden haben, gesondert an. Hier sind die Gesamtzablen angegeben. Die Krim ist nicht mit eingerechnet, sowohl für 2010 als auch für 2015. Aufgrund des Konflikts im Donbass wurden die Wablen nur in Gemeinden durchgeführt, die von der ukrainischen Regierung kontrolliert werden.

Quelle: Zentrale Wahlkommission der Ukraine, <http://www.cvk.gov.ua/wvm2015/pvm003pt001f01=100pt00_t001f01=100.html> und Berechnungen der Redaktion der Ukraine-Analysen.

\section{Grafik 3: Die Regionen der Ukraine}

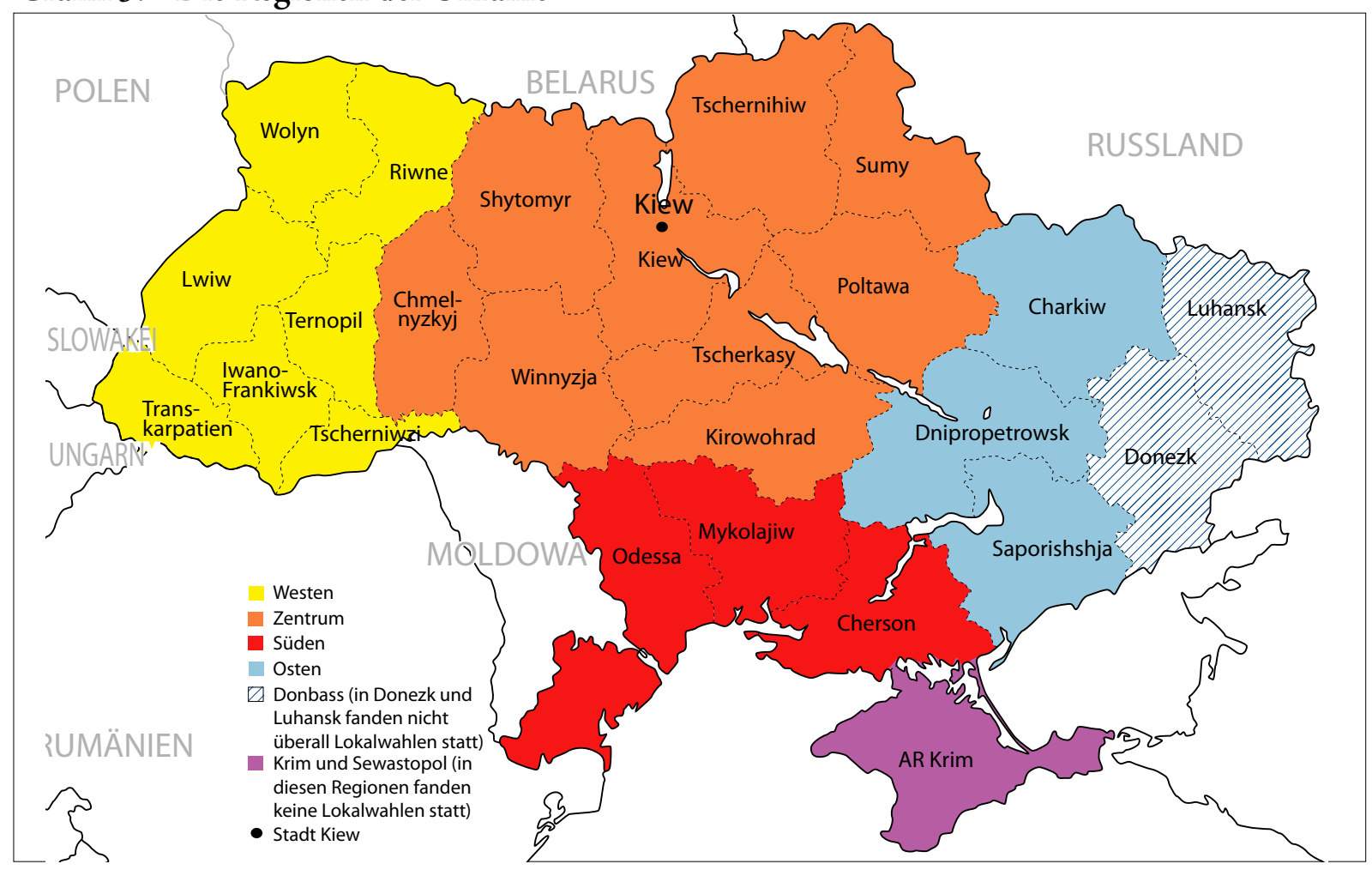

Karte: <http://english.freemap.jp/>, angepasst durch die Redaktion der Ukraine-Analysen 
Tabelle 1: Anzahl der Abgeordnetenmandate in Gemeinderäten nach Regionen bei den Lokalwahlen 2015 und 2010

\begin{tabular}{|c|c|c|c|c|c|c|c|}
\hline \multirow[t]{2}{*}{ Region* } & \multicolumn{2}{|c|}{ Anzahl der Mandate } & \multirow{2}{*}{$\begin{array}{c}\text { Rück- } \\
\text { gang, \% }\end{array}$} & \multicolumn{2}{|c|}{ Einwohnerzahl } & \multicolumn{2}{|c|}{ Einwohner pro Mandat } \\
\hline & 2015 & 2010 & & $\begin{array}{c}\text { September } \\
2015\end{array}$ & $\begin{array}{c}\text { September } \\
2010\end{array}$ & 2015 & 2010 \\
\hline West & 47.226 & 63.294 & 25,4 & 9.357 .423 & 9.354 .795 & 198 & 148 \\
\hline Zentrum & 72.103 & 91.351 & 21,1 & 14.608 .009 & 14.826 .930 & 203 & 162 \\
\hline Süd & 17.768 & 22.285 & 20,3 & 3.551 .350 & 4.663 .496 & 200 & 209 \\
\hline Ost & 19.252 & 23.865 & 19,3 & 7.737 .679 & 7.898 .592 & 402 & 331 \\
\hline Donbass & 5.660 & 16.911 & 66,5 & $6.486 .366^{* *}$ & 6.742 .791 & 1.146 & 399 \\
\hline Ukraine gesamt & 162.009 & 217.706 & & 41.740 .827 & 43.486 .604 & & \\
\hline
\end{tabular}

* Für die Anordnung der Regionen siehe Grafik 3 auf S. 22; ** vorläufige Daten.

Anmerkung: 2015 wurden manche Gemeinden vergrößert. Die Zentrale Wablkommission der Ukraine gibt die Zahlen für die Gemeinden, in denen die Wahlen turnusmäßig und erstmalig stattgefunden haben, gesondert an. Hier sind die Gesamtzahlen angegeben. Die Krim ist nicht mit eingerechnet, sowohl für 2010 als auch für 2015. Aufgrund des Konflikts im Donbass wurden die Wahlen nur in Gemeinden durchgeführt, die von der ukrainischen Regierung kontrolliert werden.

Quelle: Berechnungen der Redaktion der Ukraine-Analysen nach Angaben der Zentralen Wablkommission der Ukraine und des Statistikamts der Ukraine.

\section{Grafik 4: Beteiligung an den Lokalwahlen 2015 nach Regionen (in \%)}

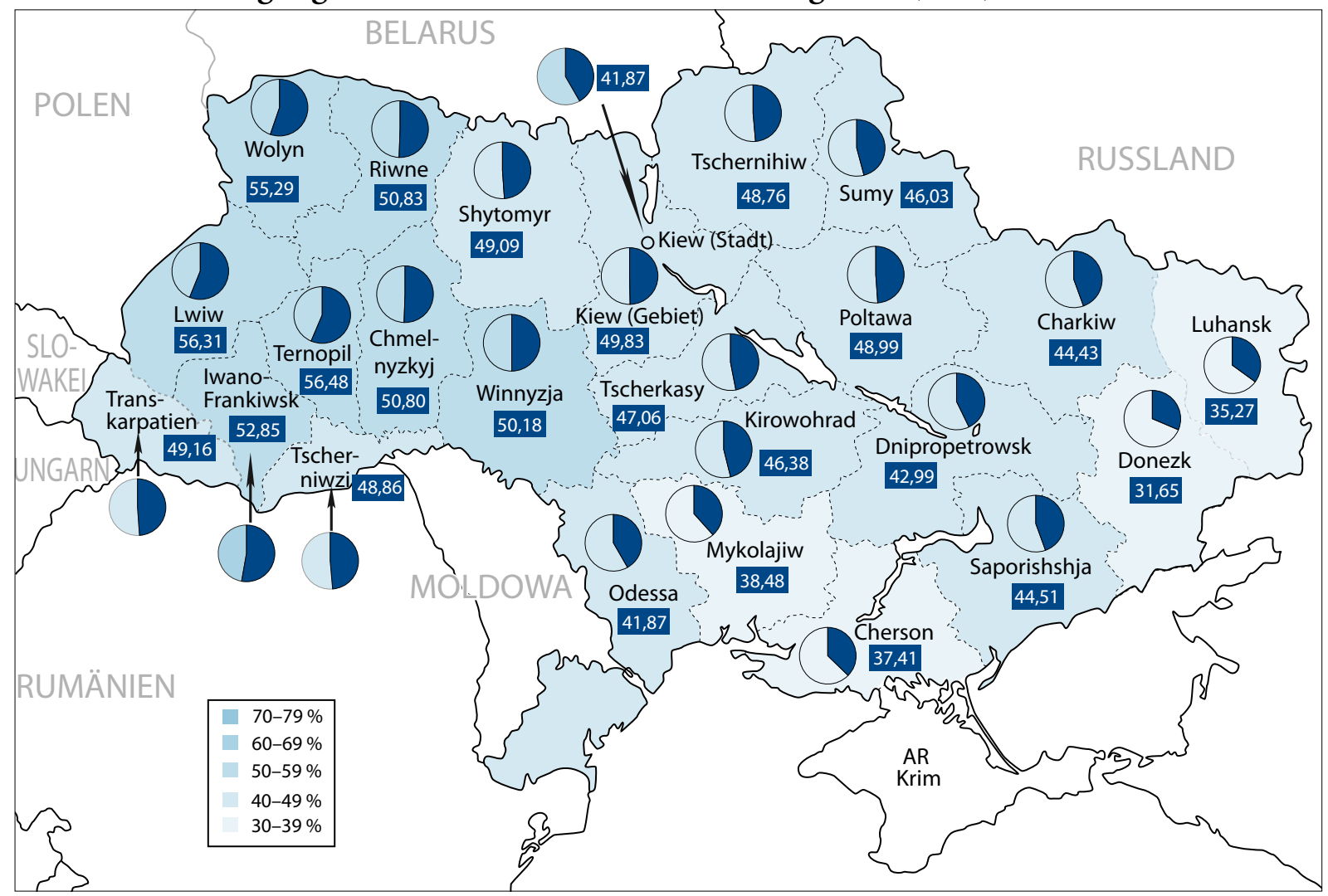

Anmerkung: Es gab keine Wablen auf der Krim. Aufgrund des Konflikts im Donbass wurden die Wablen nur in Gemeinden durchgeführt, die von der ukrainischen Regierung kontrolliert werden.

Quelle: Zentrale Wahlkommission der Ukraine, <http://www.cvk.gov.ua/vm_2015/yavka_po_reg_vm_2015.pdf>; Karte: <http:// english.freemap.jp/> 
Tabelle 2: Vorläufige Ergebnisse der Bürgermeister-, Siedlungs- und Dorfvorsteherwahlen nach Parteien

\begin{tabular}{|c|c|c|c|}
\hline Nr. & Partei & Anzahl erhaltener Sitze & $\begin{array}{c}\% \text { der Gesamtzahl neuer } \\
\text { Amtsträger }\end{array}$ \\
\hline 1 & BPP-Solidarität, UDAR & 678 & 6,6 \\
\hline 2 & Vaterland & 498 & 4,9 \\
\hline 3 & Agrarpartei & 206 & 2,0 \\
\hline 4 & Unsere Region & 165 & 1,6 \\
\hline 5 & Oppositionsblock & 89 & 0,9 \\
\hline 6 & Freiheit & 83 & 0,8 \\
\hline 7 & Wiedergeburt & 75 & 0,7 \\
\hline 8 & UKROP & 47 & 0,5 \\
\hline 9 & $\begin{array}{l}\text { Radikale Partei von Oleh } \\
\text { Ljaschko }\end{array}$ & 47 & 0,5 \\
\hline 10 & Selbsthilfe & 16 & 0,2 \\
\hline 11 & $\begin{array}{l}\text { Volksfront, Front der } \\
\text { Veränderungen }\end{array}$ & 9 & 0,1 \\
\hline \multirow[t]{7}{*}{12} & Andere Parteien & 487 & 4,8 \\
\hline & selbstaufgestellte Parteilose & 7.661 & 75,0 \\
\hline & $\begin{array}{l}\text { noch keine Ergebnisse } \\
\text { vorhanden }\end{array}$ & 75 & 0,7 \\
\hline & Stichwahl steht noch aus & 67 & 0,7 \\
\hline & $\begin{array}{l}\text { Wahlen haben nicht statt- } \\
\text { gefunden }\end{array}$ & 7 & 0,1 \\
\hline & Gesamt & 10.210 & 100,0 \\
\hline & $\begin{array}{l}\text { Regierungskoalition } \\
(1+2+10+11)\end{array}$ & 1.201 & 11,9 \\
\hline
\end{tabular}

Anmerkung: Bei der Berechnung der von einer Partei erhaltenen Sitze wurden sowohl diejenigen berücksichtigt, die von einer Partei aufgestellt wurden, als auch die Amtsträger, die in ihrer Kurzvita eine Parteizugehörigkeit angegeben haben, von dieser Partei aber nicht nominiert wurden, sondern sich selbst aufgestellt haben. 2015 wurden manche Gemeinden vergrößert. Die Zentrale Wahlkommission der Ukraine gibt die Zablen für die Gemeinden, in denen die Wablen turnusmäßig und erstmalig stattgefunden haben, gesondert an. Hier sind die Gesamtzahlen angegeben. Es gab keine Wablen auf der Krim. Aufgrund des Konflikts im Donbass wurden die Wablen nur in Gemeinden durchgeführt, die von der ukrainischen Regierung kontrolliert werden.

Quelle: Zentrale Wahlkommission der Ukraine. Zusammenstellung der Redaktion der Ukraine-Analysen. 


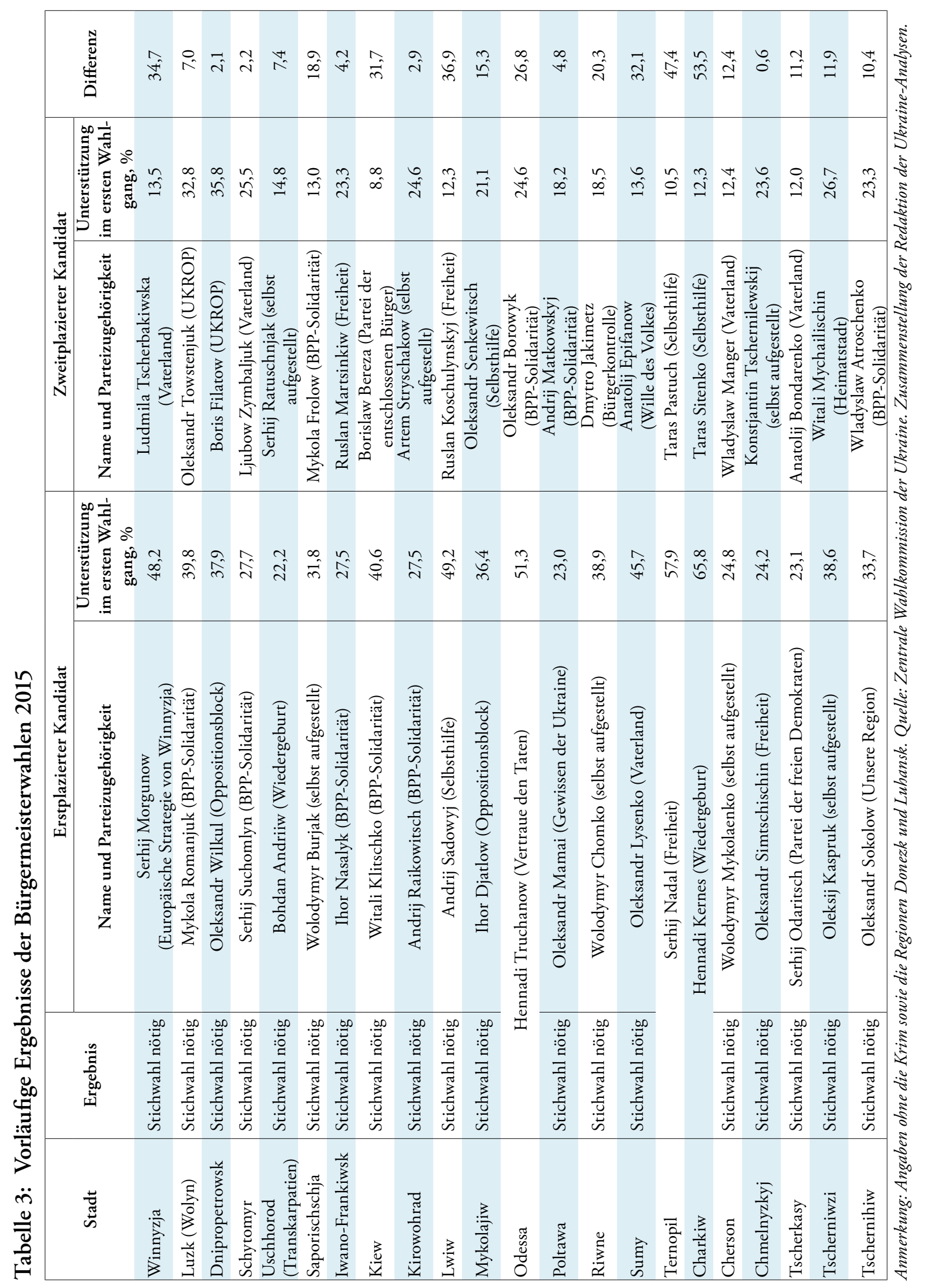


Grafik 5: Ergebnisse der Parteien bei den Wahlen 2015 zu den Regionalparlamenten

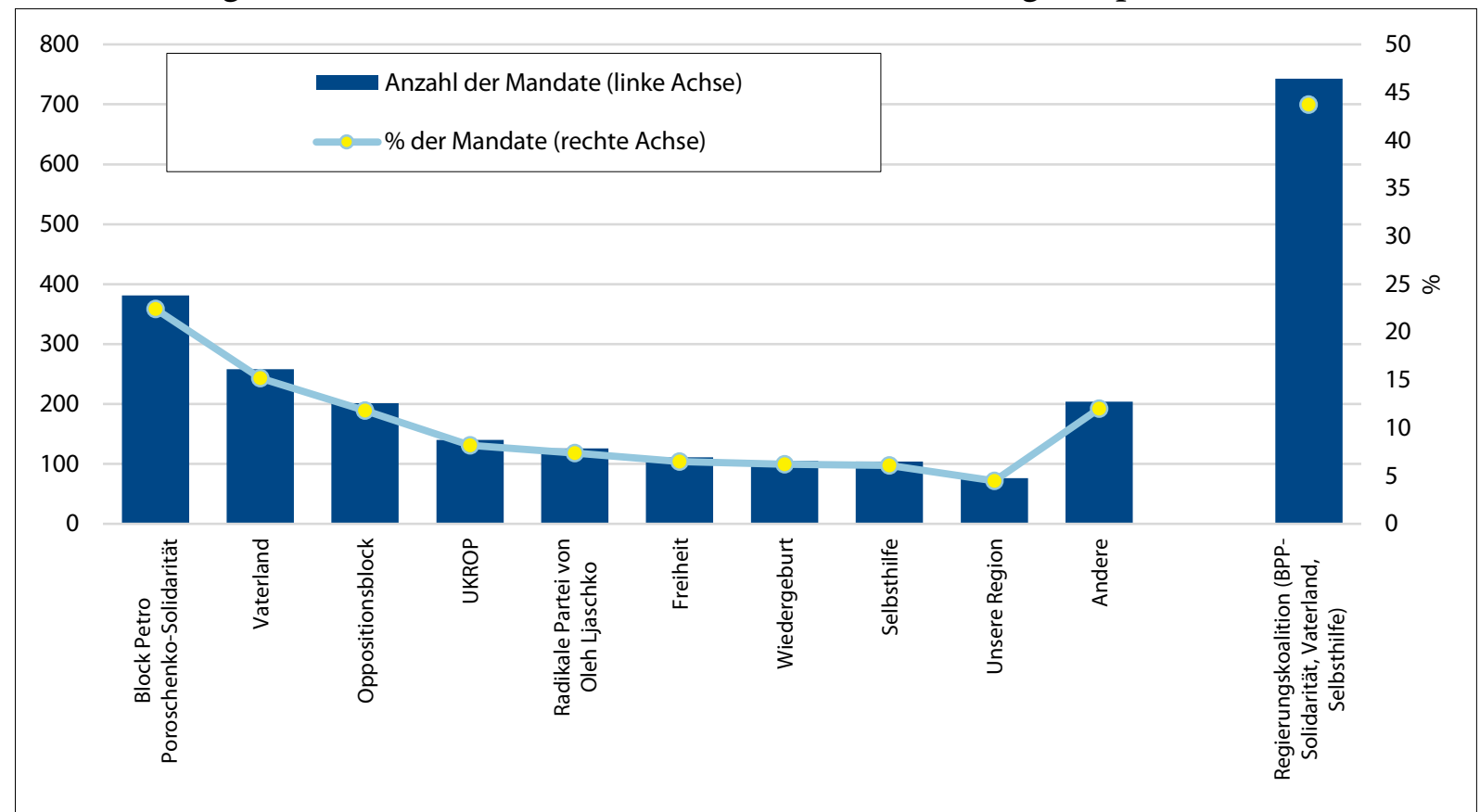

Anmerkung: Daten ohne die Krim sowie die Regionen Donezk und Luhansk

Quelle: Zentrale Wahlkommission der Ukraine. Berechnungen der Redaktion der Ukraine-Analysen.

Tabelle 4: Ergebnisse der Parteien bei den Wahlen 2015 zu den Regionalparlamenten

\begin{tabular}{|c|c|c|c|}
\hline & Anzahl der Mandate & $\%$ der Mandate & $\begin{array}{c}\text { Einzug in die } \\
\text { Regionalparlamente }\end{array}$ \\
\hline $\begin{array}{l}\text { Block Petro } \\
\text { Poroschenko-Solidarität }\end{array}$ & 381 & 22,4 & 22 \\
\hline Vaterland & 258 & 15,2 & 22 \\
\hline Oppositionsblock & 201 & 11,8 & 15 \\
\hline UKROP & 140 & 8,2 & 18 \\
\hline $\begin{array}{l}\text { Radikale Partei von Oleh } \\
\text { Ljaschko }\end{array}$ & 126 & 7,4 & 17 \\
\hline Freiheit & 111 & 6,5 & 14 \\
\hline Wiedergeburt & 105 & 6,2 & 8 \\
\hline Selbsthilfe & 104 & 6,1 & 14 \\
\hline Unsere Region & 76 & 4,5 & 10 \\
\hline Andere & 204 & 12,0 & - \\
\hline $\begin{array}{l}\text { Regierungskoalition (BPP- } \\
\text { Solidarität, Vaterland, } \\
\text { Selbsthilfe) }\end{array}$ & 743 & 43,7 & - \\
\hline Gesamt & 1700 & 100 & 22 \\
\hline
\end{tabular}

Anmerkung: Daten ohne die Krim sowie die Regionen Donezk und Luhansk

Quelle: Zentrale Wahlkommission der Ukraine. Berechnungen der Redaktion der Ukraine-Analysen. 


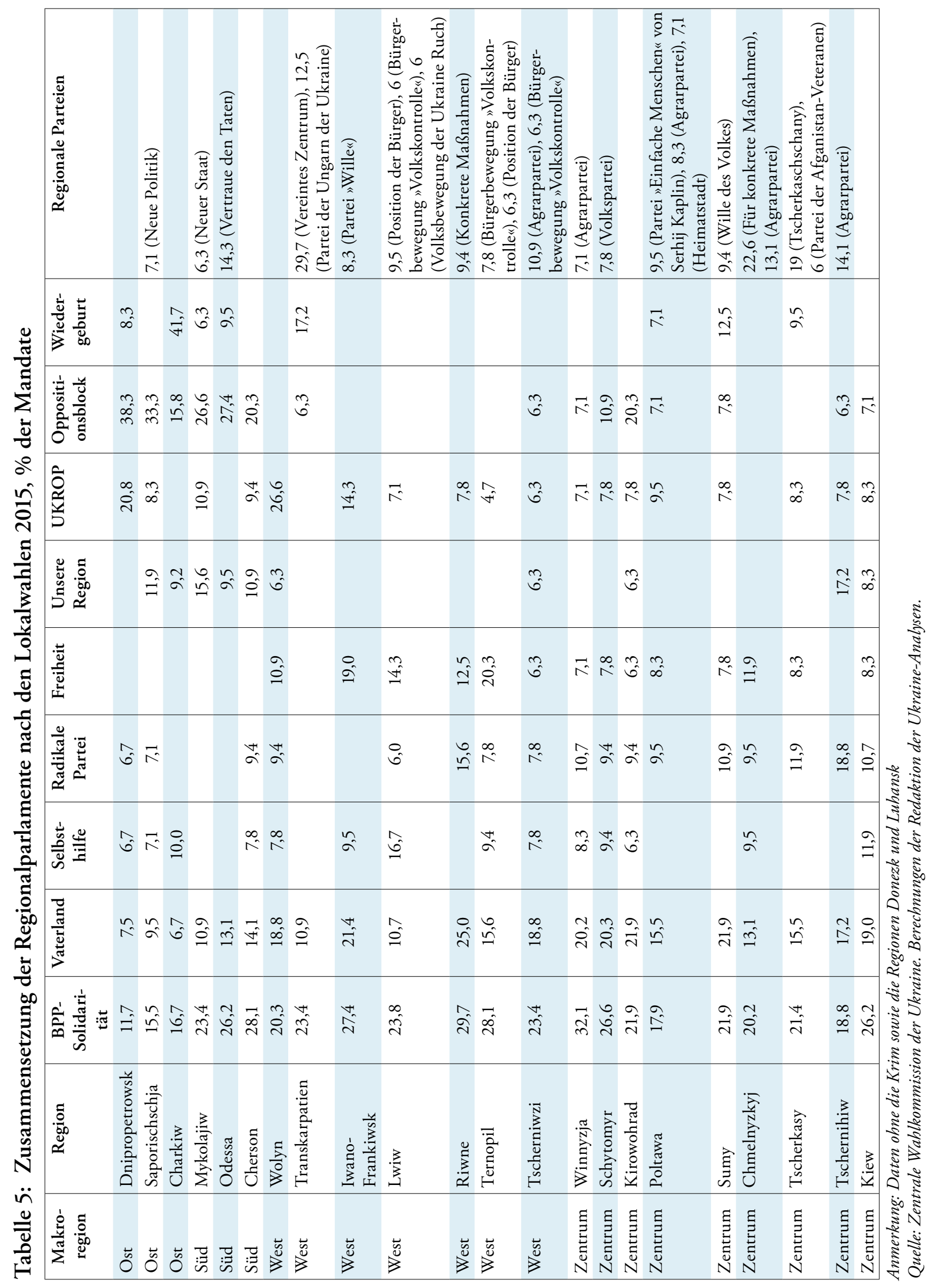


Grafik 6: Ergebnisse der Lokalwahlen nach Makroregionen*, \% der Mandate

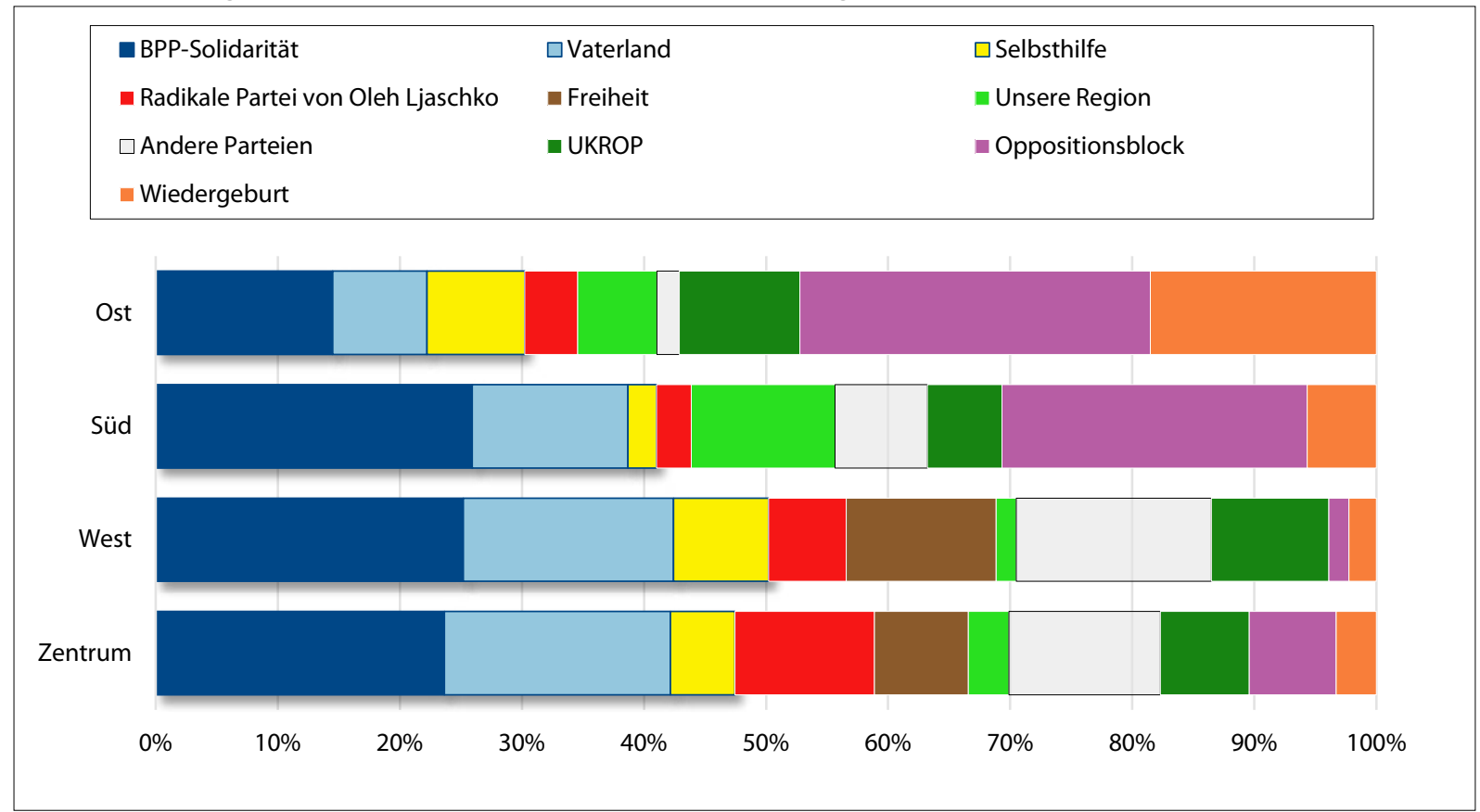

* Siehe Grafik 3 aufS. 22.

Anmerkung: Daten ohne die Krim sowie die Regionen Donezk und Luhansk

Quelle: Zentrale Wahlkommission der Ukraine. Berechnungen der Redaktion der Ukraine-Analysen.

Tabelle 6: Ergebnisse der Lokalwahlen nach Makroregionen*, \% der Mandate

\begin{tabular}{|l|c|c|c|c|}
\hline & Zentrum & West & Süd & Ost \\
\hline BPP-Solidarität & 23,6 & 25,2 & 25,9 & 14,5 \\
Vaterland & 18,5 & 17,2 & 12,7 & 7,7 \\
Selbsthilfe & 5,3 & 7,8 & 2,4 & 8,0 \\
Radikale Partei von & 11,4 & 6,4 & 2,8 & 4,3 \\
Oleh Ljaschko & 7,7 & 12,3 & 0,0 & 0,0 \\
Freiheit & 3,3 & 1,6 & 11,8 & 6,5 \\
Unser Region & 12,4 & 16,0 & 7,5 & 1,9 \\
Andere Parteien & 7,3 & 9,6 & 6,1 & 9,9 \\
UKROP & 7,1 & 1,6 & 25,0 & 28,7 \\
Oppositionsblock & 3,3 & 2,3 & 5,7 & 18,5 \\
Wiedergeburt & & & \\
\hline
\end{tabular}

* Siehe Grafik 3 aufS. 22.

Anmerkung: Daten ohne die Krim sowie die Regionen Donezk und Luhansk

Quelle: Zentrale Wahlkommission der Ukraine. Berechnungen der Redaktion der Ukraine-Analysen. 


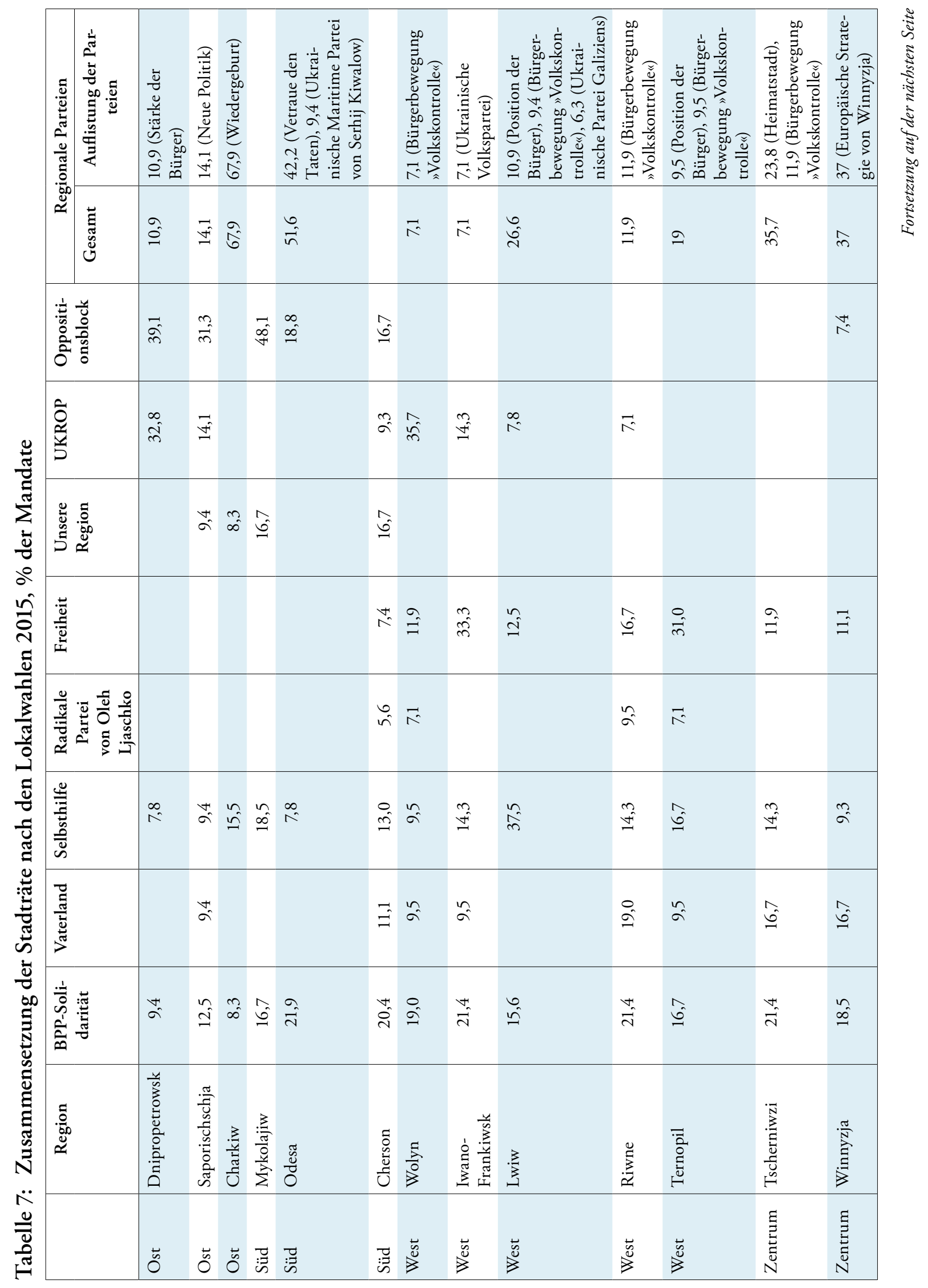




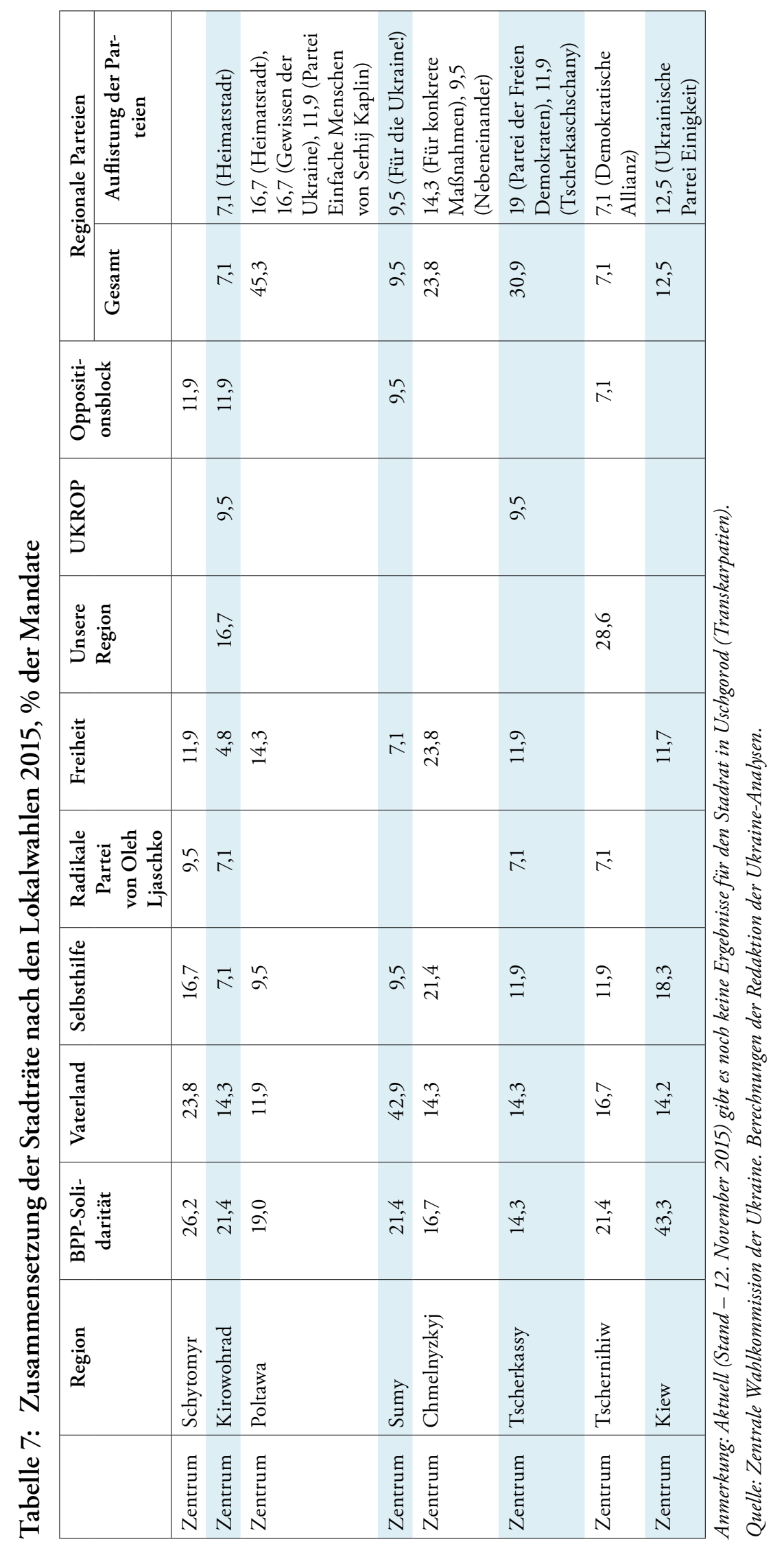




\section{Untersuchungsbericht des Europarates zu den Ereignissen in Odessa vom 2. Mai 2014 (Pressemitteilung)}

\section{Investigation of May 2014 events in Odesa failed to comply with requirements of European Human Right Convention, says International Advisory Panel's report}

Kyiv, 04.11.2015-The report of the International Advisory Panel on its review of the investigations into the tragic events in Odesa of May 2014 has been published and presented in Kyiv today. The Panel has found that the investigations have failed to satisfy the requirements of the European Convention of Human Rights.

The clashes in the centre of Odesa and the fire in the Trade Union Building on 2 May 2014 resulted in 48 deaths and injuries to several hundreds of persons.

The Ukrainian authorities initiated three investigations. The first investigation covers the conduct of the police on 2 May 2014 and the release of detainees on 4 May 2014 after protesters attacked the local police station. The second investigation focuses on the mass disorder in the city centre, and the fire in the Trade Union Building. The third one investigates the conduct of the State Emergency Service (SES) staff during the fire.

The Panel found that the investigations faced significant challenges but noted that these challenges "cannot excuse any failings which did not inevitably flow from them". The authorities were, and are under, an obligation to take all reasonable steps to ensure that the investigations comply with Article 2 (Right to life) and Article 3(Prohibition of torture and inhuman and degrading treatment) of the Convention.

The Panel considered that the second and third investigations lacked institutional and practical independence. Given the evidence indicative of police complicity in the mass disorder of 2 May 2014 and the hierarchical relationship between the SES and the Ministry of the Interior, the investigations as a whole should have been carried by an organ independent of the Ministry.

The Panel further considered that the investigations were ineffective for a number of reasons: in particular, the division of the investigative work was inefficient and the resources allocated were inadequate. The quality of the investigation was also deficient, the authorities failing to show sufficient thoroughness and diligence in initiating and pursuing the investigations. The "most striking example of a lack of diligence", in the Panel's view, was that the first real efforts to investigate an unexplained delay of over 40 minutes in the arrival of fire-fighters to the Trade Union Building, were not made until December 2014.

The Panel also addressed the question of the prosecution and trial of suspects. It expressed serious concern about the decisions to terminate the proceedings against two suspects on the grounds of lack of evidence and noted that the repeated recusals of judges had delayed the start of criminal proceedings, and that the decision to charge 21 persons in a single indictment without individualising the charges against them had had an adverse impact on the proceedings.

As for the public scrutiny of the investigations and the involvement of the victims and next-of-kin, the Panel acknowledged that the authorities had promptly provided the public with basic information and facts but found some shortcomings, the most serious being the lack of consistency, evenness and regularity of the information provided. In contrast to the Maidan investigations, the authorities did not take any co-ordinated measures directly and regularly to inform the victims and next-of-kin about the progress of the investigations.

The Panel concluded that, as a result of these investigative deficiencies, substantial progress had not been made in the investigations into the violent events in Odesa on 2 May 2014.

The International Advisory Panel was constituted by the Secretary General of the Council of Europe in April 2014, initially to oversee the Maidan violence investigations. In September 2014, the Panel's mandate was extended to examine whether the Odesa investigations met all the requirements of the European Convention on Human Rights and the case-law of the European Court.

\section{SUMMARY OF THE PANEL'S CONCLUSIONS}

Based on its review of the investigations into the violent events in Odesa on 2 May 2014, the Panel has reached the following conclusions.

As regards the challenges facing the investigations:

The challenges confronting those responsible for the investigations into the events in Odesa on 2 May 2014 have been significant and their impact on the investigations cannot be under-estimated. However, these challenges cannot excuse 
any failings which did not inevitably flow from them. The authorities clearly were, and are, under an obligation to take all reasonable steps to ensure that the investigations comply with the requirements of Articles 2 and 3 of the Convention.

As regards the independence of the investigations:

Given the evidence indicative of police complicity in the mass disorder of 2 May 2014 in Odesa, Articles 2 and 3 require that the investigation into the mass disorder as a whole be carried out by an organ entirely independent from the police. Similarly, the investigation into the conduct of the fire service cannot be regarded as independent, given the structural links between the SES and the MoI. These concerns again highlight the need for an independent and effective mechanism for the investigation of serious human rights violations committed by law enforcement officers and other public officials.

In addition, the Panel considers that it is of central importance for the purposes of maintaining the confidence of all sectors of the public in the criminal justice system that the authorities, including the judicial authorities, are seen to act in an impartial and equal manner in the conduct of the investigations and court proceedings.

As regards the effectiveness of the investigations:

Organisation of the investigative work: The Panel finds the division of investigative work between the PGO and the MoI to be inefficient and detrimental to the effectiveness of the investigations, given that they concern the same set of closely connected events and overlap to a certain extent as regards evidence, witnesses and victims. The Panel also finds that the quality, progress and effectiveness of the investigations were affected by the decision to allocate the investigation of the actions of the SES to the local MoI, which remained inactive during the crucial early stages.

Staffing and resources: The Panel finds it commendable that both the PGO and the MoI have sought to ensure continuity as regards the main investigators in Odesa. However, it finds that the reduction of each authority's investigating team has had a detrimental effect on the progress, quality and effectiveness of investigations and it considers the current staffing levels to be inadequate.

Quality of the investigations: The Panel finds that, in respect of each of the matters under investigation, the relevant authorities failed to show sufficient thoroughness and diligence in initiating and/or pursuing the investigations, with the result that their overall effectiveness was compromised.

Prosecution and trial: The Panel expresses serious concern about the decisions to terminate the proceedings against two suspects on the grounds of lack of evidence.

The Panel finds that the repeated recusals of judges led to delays in the commencement of the criminal proceedings as a whole. The Panel further finds that the decision to charge 21 individuals in a single indictment, without individualising the charges, has contributed to the delay and risks having an adverse impact on the progress of the court proceedings.

\section{As regards requirement of promptness and of reasonable expedition:}

The Panel considers that the investigation into the conduct of the SES staff was neither promptly commenced nor pursued with reasonable expedition. The investigations into the mass disorder and the fire on 2 May 2014 and into the conduct of the police on 2 and 4 May 2014, while promptly instituted, have been subject to a number of deficiencies that have significantly protracted the investigative response.

\section{As regards public scrutiny of the investigations:}

The Panel considers that the events in Odesa on 2 May 2014 were of such importance that the authorities were required to provide sufficient information about the investigations to facilitate meaningful public scrutiny. While the authorities provided a considerable amount of information, there was no effective communication policy in place, with the result that some of the information provided was difficult to understand, inconsistent, and unevenly presented and was provided with insufficient regularity.

\section{As regards involvement of victims and next-of-kin:}

The Panel's role is not to determine whether the investigation of an individual case satisfied the requirements of the Convention and, in this regard, it limits its conclusions to recalling the case-law of the European Court relating to the involvement of victims and next-of-kin in any criminal investigation. 
The Panel notes with regret that, in contrast to the Maidan investigations, the investigatory authorities did not take any co-ordinated measures directly and regularly to ensure that victims and next-of-kin were informed about the progress of the investigations. It finds that the information provided to the general public was not of itself sufficient to protect the rights and legitimate interests of the victims and next-of-kin.

As regards the Panel's evaluation of the current status of investigations:

The Panel considers that substantial progress has not been made in the investigations into the violent events in Odesa on 2 May 2014. While this outcome may be explained to some extent by the contextual challenges, the Panel considers that the deficiencies identified in this Report have undermined the authorities' ability to establish the circumstances of the Odesa-related crimes and to bring to justice those responsible.

Quelle: $<$ https://wcd.coe.int/ViewDoc.jsp?Ref=DC-PR155\%282015\%29\&Language=lanEnglish\&Ver=original\&Site=DC\&Back ColorInternet=F5CA75\&BackColorIntranet=F5CA75\&BackColorLogged=A9BACE $>$ 


\section{Oktober - 8. November 2015}

\begin{tabular}{|c|c|}
\hline 26.10 .2015 & $\begin{array}{l}\text { ie Wahlbeobachterorganisation OPORA weist Meldungen des Blocks Petro Poroschenko zurück, nach denen } \\
\text { Lysytschansk im Gebiet Donezk die Lokalwahlen für ungültig erklärt worden seien. Dort liegt vor Auszäh- } \\
\text { ng aller Stimmen der Kandidat des Oppositionsblocks vorn. }\end{array}$ \\
\hline 26.10.2015 & $\begin{array}{l}\text { Die OSZE und die Wahlbeobachterorganisation OPORA bewerten die Lokalwahlen vom } 25.10 .2015 \text { in ersten } \\
\text { Stellungnahmen grundsätzlich positiv. Laut OPORA sei der Missbrauch administrativer Ressourcen - d. h. der } \\
\text { Einsatz staatlicher Mittel für die Kampagnen von Amtsinhabern - erheblich geringer als im Jahr 2010. Gleich- } \\
\text { wohl sei in } 18 \% \text { der Wahllokale beobachtet worden, dass Wahlzettel ohne Überprüfung des Ausweises ausgehän- } \\
\text { digt wurden. Schwerere Verstöße wie etwa das Fotografieren von Wahlzetteln seien in } 2 \% \text { der Wahllokale regis- } \\
\text { triert worden. In einigen Städten sei Stimmenkauf beobachtet worden. Im Vergleich zu den Parlamentswahlen } \\
\text { von } 2012 \text { und } 2014 \text { hätten sich die Ermittlungsbehörden jedoch aufnahmebereiter für Hinweise aus der Bevöl- } \\
\text { kerung und von zivilgesellschaftlichen Organisationen gezeigt. }\end{array}$ \\
\hline 26.10.2015 & $\begin{array}{l}\text { Laut der Wahlbeobachterorganisation OPORA liegt die Wahlbeteiligung bei den Lokalwahlen im ukrainisch } \\
\text { kontrollierten Teil des Donbass bei } 37 \% \text {. Die Zentrale Wahlkommission beziffert die Wahlbeteiligung hingegen } \\
\text { auf } 32 \% \text { im Gebiet Donezk und auf } 35 \% \text { im Gebiet Luhansk. Landesweit habe sie bei } 47 \% \text { gelegen. }\end{array}$ \\
\hline 27.10 .2015 & $\begin{array}{l}\text { inisterpräsident Arsenij Jazenjuk erklärt, dass die Ukraine ihre Schulden an Russland nicht zurückzahlen werde, } \\
\text { lange Russland sich nicht auf die Restrukturierung der Forderungen einlasse. Russland hatte der Ukraine noch } \\
\text { tter Präsident Wiktor Janukowytsch im Jahr } 2013 \text { einen Kredit in Höhe von drei Milliarden US-Dollar ausge- } \\
\text { hlt, den es bis Ende des Jahres } 2015 \text { zurückfordert. Die von der Ukraine anvisierte Restrukturierung beinhal- } \\
\text { t eine Laufzeitverlängerung. }\end{array}$ \\
\hline 27.10 .2015 & $\begin{array}{l}\text { Präsident Petro Poroschenko kritisiert, dass die Separatisten der "Volksrepubliken« von Donezk und Luhansk die } \\
\text { ursprünglich für den Herbst des Jahres } 2015 \text { geplanten Lokalwahlen nicht abgesagt, sondern lediglich verscho- } \\
\text { ben haben. Auf einem Treffen der Staats- und Regierungschefs Russlands, der Ukraine, Deutschlands und Frank- } \\
\text { reichs Anfang Oktober } 2015 \text { war beschlossen worden, darauf hinzuwirken, dass Wahlen nur im Einklang mit } \\
\text { der ukrainischen Gesetzgebung stattfinden. Der Vertreter der Ukraine in der Arbeitsgruppe zu politischen Fra- } \\
\text { gen, Roman Bessmertnyj, erklärt, es könnten lokalspezifische Änderungen des Wahlgesetzes vorgenommen wer- } \\
\text { den, jedoch müssten Grundvoraussetzungen erfüllt sein. Dazu zählten politischer Pluralismus und Pressefreiheit. } \\
\text { Außerdem müssten die Gebiete vollständig minenfrei und entmilitarisiert sein, alle ausländischen Soldaten müss- } \\
\text { ten das Gebiet verlassen und der ukrainische Staat müsse die Kontrolle über das Territorium wiedererlangt haben. }\end{array}$ \\
\hline 27.10.2015 & $\begin{array}{l}\text { ie Kontaktgruppe aus Vertretern der Ukraine, Russlands und der OSZE in Minsk einigt sich mit Vertretern der } \\
\text { paratisten auf einen Gefangenenaustausch. Er soll am 29. Oktober } 2015 \text { stattfinden. }\end{array}$ \\
\hline 28.10.2015 & $\begin{array}{l}\text { ie Ukraine wird im Doing-Business-Rating der Weltbank-Gruppe um } 13 \text { Plätze höher eingestuft als im letzten } \\
\text { ating. Die Internetzeitung Ukrainska Prawda bemerkt, dass sich die Berechnungsmethode des Ratings im vergan- } \\
\text { nen Jahr geändert habe. Nach der vorherigen Methode wäre die Ukraine um vier Plätze höher eingestuft worden. }\end{array}$ \\
\hline 28.10.2015 & $\begin{array}{l}\text { In Pawlohrad im Gebiet Dnipropetrowsk sagt die Zentrale Wahlkommission die Stichwahl zwischen zwei Kan- } \\
\text { didaten um das Bürgermeisteramt ab. Sie beruft sich dabei auf eine vor wenigen Tagen erlassene Anordnung, der } \\
\text { zufolge in Städten mit weniger als } 90.000 \text { Wählern keine Stichwahl durchgeführt werde. Entgegen einer offi- } \\
\text { ziellen Zählung im August } 2015 \text { war die Kommission zu dem Ergebnis gekommen, dass die Anzahl der Wähler } \\
\text { in der Stadt auf unter } 90.000 \text { gefallen sei. Die Wahlbeobachterorganisation OPORA, das „Wählerkomitee der } \\
\text { Ukraine« und auch Präsident Petro Poroschenko protestieren gegen die Entscheidung. Innenminister Arsen Awa- } \\
\text { kow nennt die Entscheidung einen Rechtsbruch, der gerichtlich verfolgt werde. Am Mittag gibt die lokale Wahl- } \\
\text { kommission schließlich bekannt, dass doch eine Stichwahl stattfinden werde. Ein Kiewer Gericht erklärt am Fol- } \\
\text { getag die Absage der Stichwahl für unrechtmäßig. }\end{array}$ \\
\hline 29.10 .2015 & $\begin{array}{l}\text { Nachdem am 25. Oktober } 2015 \text { aufgrund beidseitiger Verbote der Flugverkehr zwischen Russland und der Ukraine } \\
\text { vollständig eingestellt wurde, erklärt der Minister für Infrastruktur, Wolodymyr Schulmejster, man werde das Ver- } \\
\text { bot gegen russische Fluglinien erst wieder aufheben, wenn Russland eine Strafe für Flüge auf die Krim bezahle. }\end{array}$ \\
\hline 29.10 .2015 & Laut dem ukrainischen Generalstab kommt bei der Explosion eines Sprengsatzes ein Soldat ums Leben. \\
\hline 29.10 .2015 & $\begin{array}{l}\text { Im Gebiet Luhansk kommt es zu einem Gefangenenaustausch zwischen ukrainischen Kräften und den Separatis- } \\
\text { ten. Elf Angehörige der separatistischen Truppen sowie neun Kämpfer der ukrainischen Streitkräfte kommen frei. }\end{array}$ \\
\hline 29.10 .2015 & $\begin{array}{l}\text { In der ukrainisch kontrollierten Stadt Swatowe im Gebiet Luhansk kommt es zu einem Brand in einem Muniti- } \\
\text { onslager. Teilweise erreichen explodierende Granaten auch die umliegenden Gebäude. Zwei Menschen kommen } \\
\text { ums Leben, darunter ein Zivilist. }\end{array}$ \\
\hline
\end{tabular}




\begin{tabular}{|c|c|}
\hline 30.10 .2015 & $\begin{array}{l}\text { Medien berichten, dass die Europäische Kommission die Rolle des Generalstaatsanwalts Wiktor Schokin bei der } \\
\text { Einrichtung einer speziellen Korruptionsermittlungsbehörde missbilligt. Er habe zu viel Einfluss auf die Ausge- } \\
\text { staltung der Behörde, die vollkommen unabhängig von der Staatsanwaltschaft sein solle. Die Behörde ist eine } \\
\text { Bedingung der EU für weitere Verhandlungen zur Visafreiheit. Auch der US-Botschafter in der Ukraine, Geof- } \\
\text { frey Pyatt, kritisiert Schokin. Er wehre sich gegen Reformen seiner Behörde und schütze korrupte Staatsanwälte. }\end{array}$ \\
\hline 30.10 .2015 & $\begin{array}{l}\text { Laut einer Rangliste der } 100 \text { reichsten Ukrainer, zusammengestellt vom Magazin Nowoe Wremja, haben die } \\
\text { zehn reichsten Ukrainer im laufenden Jahr erhebliche finanzielle Einbußen erlitten. Lediglich die Geschäfte des } \\
\text { Präsidenten Petro Poroschenko entwickelten sich trotz der anhaltenden Wirtschaftskrise gut. Er steigt mit einem } \\
\text { geschätzten Vermögen von } 979 \text { Millionen US-Dollar von Platz neun auf Platz sechs der Liste. }\end{array}$ \\
\hline 30.10 .2015 & $\begin{array}{l}\text { Bei der Kiewer Bürgermeisterwahl erhält der amtierende Bürgermeister Witalij Klitschko } 41 \% \text { der Stimmen. Er } \\
\text { wird in einer Stichwahl gegen den zweitplatzierten Borislaw Beresa von der Partei Entschlossener Bürger antre- } \\
\text { ten, der } 9 \% \text { der Stimmen erhielt. }\end{array}$ \\
\hline 30.10 .2015 & $\begin{array}{l}\text { Bei einem Schusswechsel bei dem Dorf Piski nordwestlich von Donezk kommt nach Angaben des Generalstabs } \\
\text { ein Soldat der ukrainischen Armee ums Leben. }\end{array}$ \\
\hline 31.10 .2015 & $\begin{array}{l}\text { In Dnipropetrowsk findet eine gemeinschaftliche Razzia der Generalstaatsanwaltschaft und des Inlandsgeheim- } \\
\text { dienstes SBU in den Räumen des "Fonds zur Landesverteidigung"statt, die Spenden für die Unterstützung der } \\
\text { "Anti-Terror-Operation« sammelt. Laut Angaben der Behörden habe man eine erhebliche Zahl an Waffen gefun- } \\
\text { den und gehe davon aus, dass mit den Spendengeldern eine Privatarmee finanziert wurde, die sich am örtlichen } \\
\text { Schmuggel beteiligte. Auch die Räume des Kandidaten für die Kiewer Bürgermeisterwahl, Hennadyj Korban } \\
\text { von der Partei Ukrop, werden durchsucht, er selbst wird festgenommen. Die Generalstaatsanwaltschaft erklärt, } \\
\text { man ermittle, ob Korban mit der Organisation zu tun habe. Am Abend versammeln sich etwa } 800 \text { Anhänger der } \\
\text { Partei Ukrop in Dnipropetrowsk und protestieren gegen die Festnahme Korbans und die Durchsuchungen des } \\
\text { Fonds zur Landesverteidigung. }\end{array}$ \\
\hline 01.11 .2015 & $\begin{array}{l}\text { Der stellvertretende Fraktionschef des Blocks Petro Poroschenko, Ihor Kononenko, erklärt, die Festnahme des Vor- } \\
\text { sitzenden der Partei Ukrop, Hennadyj Korban, habe keine politische Dimension. Der Unternehmer Ihor Kolomojs- } \\
\text { kij hingegen erklärt, die Festnahme Korbans stehe im Zusammenhang mit dem guten Wahlergebnis von UKROP. } \\
\text { Er beschuldigt den Präsidenten Petro Poroschenko, die Festnahme initiiert zu haben. Korban, der als enger Ver- } \\
\text { trauter Kolomojskijs gilt, war am Vortag in Dnipropetrowsk im Zusammenhang mit einer Razzia beim Fonds } \\
\text { zur Landesverteidigung festgenommen worden, dem die Veruntreuung von Spendengeldern vorgeworfen wird. }\end{array}$ \\
\hline 02.11 .2015 & $\begin{array}{l}\text { Die Organisation Transparency International wirft dem Generalstaatsanwalt Wiktor Schokin vor, im Einver- } \\
\text { ständnis mit der politischen Führung des Landes Einfluss auf die Gestaltung der neu zu bildenden Anti-Kor- } \\
\text { ruptions-Ermittlungsbehörde auszuüben. So wolle man sicherstellen, dass die eigenen Aktivitäten nicht von der } \\
\text { Behörde belangt werden können. }\end{array}$ \\
\hline 02.11 .2015 & $\begin{array}{l}\text { Am Abend werden zwei Schüsse auf die Fenster des Arbeitszimmers des Generalstaatsanwalts Wiktor Schokin } \\
\text { abgefeuert, während Schokin sich dort zu Gesprächen aufhält. Niemand wird verletzt. Militärastaatsanwalt Ana- } \\
\text { tolij Mitjus erklärt später, das Panzerglas habe verhindert, dass die Projektile in den Raum eindringen konnten. }\end{array}$ \\
\hline 03.11 .2015 & $\begin{array}{l}\text { Vor dem Parlamentsgebäude demonstrieren einige Hundert Menschen für die Freilassung von Hennadyj Korban, } \\
\text { der im Zusammenhang mit der Durchsuchung einer Organisation zur Unterstützung der ukrainischen Armee } \\
\text { in Dnipropetrowsk festgenommen wurde. Die Staatsanwaltschaft wirft der Stiftung vor, Spendeneinnahmen für } \\
\text { den Aufbau einer Privatarmee missbraucht zu haben. Korban, der der Partei Ukrop vorsteht, soll dem Unterneh- } \\
\text { mer Ihor Kolomoskyj nahestehen. }\end{array}$ \\
\hline 04.11 .2015 & $\begin{array}{l}\text { Der Europarat kritisiert die ukrainischen Behörden für die Untersuchung der Ereignisse vom 2. Mai } 2014 \text { in Odessa. } \\
\text { Dort waren nach Ausschreitungen zwischen Demonstranten des »Anti-Maidan«, pro-ukrainischen Aktivisten und Natio- } \\
\text { nalisten } 48 \text { Menschen bei einem Feuer ums Leben gekommen - mehrheitlich Angehörige des Anti-Maidan. Der pro- } \\
\text { ukrainischen Seite war Brandstiftung vorgeworfen worden, was die Staatsanwaltschaft am 22. April } 2014 \text { bestritten hatte. } \\
\text { Der Bericht des Europarates betont jedoch nun, die Untersuchung der Brandursache sei nicht unabhängig verlaufen. }\end{array}$ \\
\hline 04.11 .2015 & $\begin{array}{l}\text { Der Sprecher des Nationalen Sicherheitsrats Oleksandr Turtschynow erklärt, dass die schweren Waffen wieder an } \\
\text { die Frontlinie gebracht würden, sollten weiterhin Separatisten provokative Angriffe auf Truppen der ukrainischen } \\
\text { Armee ausführen. Die Separatisten hätten in den vergangenen } 24 \text { Stunden neunmal den Waffenstillstand verletzt. }\end{array}$ \\
\hline 04.11 .2015 & $\begin{array}{l}\text { Iwanna Klimpusch-Zinzadse, Abgeordnete des Blocks Petro Poroschenko, erklärt, die EU habe ihren Streit mit } \\
\text { der ukrainischen Seite über die Bildung einer Ermittlungsbehörde für Korruptionsfälle beigelegt. Sie hatte der } \\
\text { Generalstaatsanwaltschaft vorgeworfen, die Gestaltung über loyale Mitglieder in der verantwortlichen Kommis- } \\
\text { sion zu beeinflussen. Beim nun gefundenen Kompromiss solle ein Teil der Kommissionsmitglieder ausgetauscht } \\
\text { werden. Das Außenministerium bestätigt später die Vereinbarung. }\end{array}$ \\
\hline
\end{tabular}




\begin{tabular}{|c|c|}
\hline 05.11 .2015 & $\begin{array}{l}\text { Das Parlament verabschiedet ein neues Arbeitsgesetzbuch, das das gesamte Arbeitsrecht kodifiziert. Das Dis- } \\
\text { kriminierungsverbot bei der Arbeitsplatzvergabe berücksichtigt nicht die sexuelle Orientierung des Bewerbers. } \\
\text { Damit wird eine wichtige Norm, die für die EU als Bedingung für die Visaliberalisierung gilt, nicht umgesetzt. } \\
\text { Für den Einschluss der Norm in das Arbeitsgesetzbuch hatten nur } 117 \text { Abgeordnete gestimmt, } 226 \text { wären für } \\
\text { eine Mehrheit notwendig gewesen. }\end{array}$ \\
\hline 05.11 .2015 & $\begin{array}{l}\text { Das Parlament verabschiedet nur zwei der dreizehn Gesetzesprojekte, die als Bedingung für die Abschaffung der } \\
\text { Visapflicht ukrainischer Bürger bei der Einreise in die EU gelten. }\end{array}$ \\
\hline 05.11 .2015 & $\begin{array}{l}\text { Elena Lukasch, Justizministerin unter Wiktor Janukowytsch, wird festgenommen. Die Staatsanwaltschaft wirft } \\
\text { ihr vor, 2,5 Millionen Hrywnja (im Jahr } 2013 \text { etwa } 250.000 \text { Euro) unterschlagen zu haben. Am Folgetag wird } \\
\text { sie verhaftet, kommt aber gegen Kaution aus der Untersuchungshaft frei. }\end{array}$ \\
\hline 06.11 .2015 & $\begin{array}{l}\text { Der Vorsitzende der Partei Ukrop, Hennadyj Korban, wird bis Ende des Jahres } 2015 \text { unter Hausarrest gestellt. } \\
\text { Das Gericht begründet den Schritt damit, dass Korban auf den Verlauf der Ermittlungen Einfluss nehmen könne. } \\
\text { Korban, der dem Unternehmer Ihor Kolomojskyj nahestehen soll, wird vorgeworfen, in organisierte Kriminali- } \\
\text { tät verwickelt zu sein. }\end{array}$ \\
\hline 07.11 & $\begin{array}{l}\text { Das Gesetz, das die bisherige Miliz durch eine "nationale Polizei« ersetzt, tritt in Kraft. Diese unterscheidet sich } \\
\text { von der Miliz in einigen Punkten. Dazu zählen die starke Anhebung des Durchschnittsgehalts von weniger als } \\
4.000 \text { auf } 8.000 \text { Hrywnja (etwa } 340 \text { Euro) im Monat, die Übernahme der Verkehrskontrollen bei gleichzeitiger } \\
\text { Abschaffung der Verkehrspolizei und die neue schwarze Uniform. }\end{array}$ \\
\hline 07.11 .2015 & $\begin{array}{l}\text { Außenminister Pawlo Klimkin fordert die Einrichtung weiterer Zentren der OSZE-Beobachtermission im Don- } \\
\text { bass - sowohl entlang der Frontlinie als auch an der russisch-ukrainischen Grenze. }\end{array}$ \\
\hline 08.11 .2015 & $\begin{array}{l}\text { Präsident Petro Poroschenko erklärt, die Ukraine habe die Forderung der EU erfüllt und die Kommission zur Bil- } \\
\text { dung einer Anti-Korruptions-Ermittlungsbehörde neu besetzt. Nach Auskünften des Internetportals Ukrainska } \\
\text { Prawda hat sich jedoch die personelle Besetzung laut einem entsprechenden Online-Dokument nicht geändert. } \\
\text { Auch sei Jurij Sewruk, auf dessen Ablösung die EU bestehe, noch immer Teil der Kommission. }\end{array}$ \\
\hline 08.11 .2015 & $\begin{array}{l}\text { Die Separatisten der "Volksrepublik Donezk» erklären, dass die ukrainische Armee das Zentrum von Donezk mit } \\
\text { Grad-Raketen angegriffen habe. Der ukrainische Generalstab bestreitet diese Information. }\end{array}$ \\
\hline 08.11 .2015 & $\begin{array}{l}\text { Ministerpräsident Arsenij Jazenjuk ruft die Abgeordneten des Parlaments dazu auf, in der kommenden Woche } \\
\text { die Gesetze anzunehmen, die für die EU eine Bedingung zur Visaliberalisierung darstellen. Diese Gesetze, die } \\
\text { zumeist der Korruptionsbekämpfung dienen, seien in allen EU-Mitgliedsstaaten in Kraft. }\end{array}$ \\
\hline
\end{tabular}

Die Chronik wird zeitnah erstellt und basiert ausschließlich auf im Internet frei zugänglichen Quellen. Die Redaktion bemüht sich, bei jeder Meldung die ursprüngliche Quelle eindeutig zu nennen. Aufgrund der großen Zahl von manipulierten und falschen Meldungen kann die Redaktion der Ukraine-Analysen keine Gewähr für die Richtigkeit der Angaben übernehmen.

Zusammengestellt von Jan Matti Dollbaum

Sie können die gesamte Chronik seit Februar 2006 auch auf <http://www.laender-analysen.de/ukraine/> unter dem Link »Chronik«lesen.

Herausgeber: Forschungsstelle Osteuropa an der Universität Bremen und Deutsche Gesellschaft für Osteuropakunde

Die Meinungen, die in den Ukraine-Analysen geäußert werden, geben ausschließlich die Auffassung der Autoren wieder.

Abdruck und sonstige publizistische Nutzung sind nach Rücksprache mit der Redaktion gestattet. Verantwortlicher Redakteur für diese Ausgabe: Katerina Bosko (geb. Malygina) Satz: Matthias Neumann

Ukraine-Analysen-Layout: Cengiz Kibaroglu, Matthias Neumann und Michael Clemens

Alle Ausgaben der Ukraine-Analysen sind mit Themen- und Autorenindex archiviert unter www.laender-analysen.de

Die Ukraine-Analysen werden im Rahmen eines Lizenzvertrages in das Internetangebot der Bundeszentrale für politische Bildung (www.bpb.de) aufgenommen. Die Ukraine-Analysen werden im Rahmen der Datenbank World Affairs Online (WAO) ausgewertet und sind im Portal IREON www.ireon-portal.de recherchierbar. ISSN 1862-555X @ 2015 by Forschungsstelle Osteuropa, Bremen

Forschungsstelle Osteuropa • Publikationsreferat • Klagenfurter Str. 3 - 28359 Bremen • Telefon: +49 421-218-69600 • Telefax: +49 421-218-69607 e-mail: publikationsreferat@osteuropa.uni-bremen.de•Internet-Adresse: http://www.laender-analysen.de/ukraine/ 


\section{Kostenlose E-Mail-Dienste der Forschungsstelle Osteuropa und ihrer Partner auf www.laender-analysen.de}

Die Länder-Analysen bieten regelmäßig im kostenlosen Abonnement kompetente Einschätzungen aktueller politischer, wirtschaftlicher, sozialer und kultureller Entwicklungen in Ostmitteleuropa und der GUS. Sie machen das Wissen, über das die wissenschaftliche Forschung in reichem Maße verfügt, für Politik, Wirtschaft, Medien und die interessierte Öffentlichkeit verfügbar. Autoren sind internationale Fachwissenschaftler und Experten.

Die einzelnen Länder-Analysen werden von der Forschungsstelle Osteuropa an der Universität Bremen und der Deutschen Gesellschaft für Osteuropakunde jeweils mit unterschiedlichen Partnern und Sponsoren herausgegeben. Die Redaktionen der Länder-Analysen bestehen aus Wissenschaftlern mit langjähriger Forschungserfahrung.

Die Länder-Analysen bieten regelmäßig Kurzanalysen zu aktuellen Themen, ergänzt um Grafiken und Tabellen sowie Dokumentationen. Zusätzlich gibt es eine Chronik aktueller Ereignisse. Alle Länder-Analysen sind auch mit Archiv und Indizes online verfügbar unter $<$ www.laender-analysen.de $>$.

\section{Belarus-Analysen}

Erscheinungsweise: zweimonatlich

Abonnement unter: <http://www.laender-analysen.de/belarus/>

\section{Caucasus Analytical Digest}

In englischer Sprache. Erscheinungsweise: monatlich

Abonnement unter: <http://www.css.ethz.ch/publications/newsletter_CAD_EN>

\section{Polen-Analysen}

Erscheinungsweise: zweimal monatlich

Abonnement unter: <http://www.deutsches-polen-institut.de/newsletter/polen-analysen/>

\section{Russland-Analysen}

Erscheinungsweise: zweiwöchentlich

Abonnement unter: <http://www.laender-analysen.de/russland/>

\section{Russian Analytical Digest}

In englischer Sprache. Erscheinungsweise: zweimal monatlich

Abonnement unter: <http://www.css.ethz.ch/publications/newsletter_RAD_EN>

\section{Ukraine-Analysen}

Erscheinungsweise: zweimal monatlich

Abonnement unter: <http://www.laender-analysen.de/ukraine/>

\section{Zentralasien-Analysen}

Erscheinungsweise: monatlich

Abonnement unter: <http://www.laender-analysen.de/zentralasien/>

\section{Bibliographische Dienste}

Die Bibliographien informieren über englisch- und deutschsprachige Neuerscheinungen zu Belarus, Russland, Ukraine sowie zu den zentralasiatischen und kaukasischen Staaten. Erfasst werden jeweils die Themenbereiche Politik, Außenpolitik, Wirtschaft und Soziales.

Erscheinungsweise: viermal jährlich

Abonnement unter: <http://www.laender-analysen.de/bibliographies/belarus.php>, <http://www.laender-analysen. de/bibliographies/russia.php>, <http://www.laender-analysen.de/bibliographies/ukraine.php>, <http://www.laenderanalysen.de/bibliographies/caucasus_ca.php> 